\title{
Effects of metformin on retinoblastoma growth in vitro and in vivo
}

\author{
KATARZYNA BRODOWSKA ${ }^{1}$, SOFIA THEODOROPOULOU ${ }^{1}$, MELISSA MEYER ZU HÖRSTE ${ }^{1}$, \\ ELEFTHERIOS I. PASCHALIS ${ }^{1}$, KIMIO TAKEUCHI ${ }^{1}$, GORDON SCOTT ${ }^{1}$, DAVID J. RAMSEY ${ }^{1}$, \\ ELIZABETH KIERNAN $^{1}$, MIEN HOANG ${ }^{1}$, JOANNA CICHY ${ }^{2}$, JOAN W. MILLER ${ }^{1}$, \\ EVANGELOS S. GRAGOUDAS ${ }^{1}$ and DEMETRIOS G. VAVVAS ${ }^{1}$ \\ ${ }^{1}$ Retina Service, Angiogenesis Laboratory, Massachusetts Eye and Ear Infirmary, Department of Ophthalmology, \\ Harvard Medical School, Boston, MA, USA; ${ }^{2}$ Department of Immunology, Faculty of Biochemistry, \\ Biophysics and Biotechnology, Jagiellonian University, Krakow, Poland
}

Received March 28, 2014; Accepted April 25, 2014

DOI: $10.3892 / \mathrm{ijo} .2014 .2650$

\begin{abstract}
Recent studies suggest that the anti-diabetic drug metformin may reduce the risk of cancer and have anti-proliferative effects for some but not all cancers. In this study, we examined the effects of metformin on human retinoblastoma cell proliferation in vitro and in vivo. Two different human retinoblastoma cell lines (Y79, WERI) were treated with metformin in vitro and xenografts of Y79 cells were established in nu/nu immune-deficient mice and used to assess the effects of pharmacological levels of metformin in vivo. Metformin inhibited proliferation of the retinoblastoma cells in vitro. Similar to other studies, high concentrations of metformin (mM) blocked the cell cycle in G0-G1, indicated by a strong decrease of G1 cyclins, especially cyclin D, cyclin-dependent kinases (4 and 6), and flow cytometry assessment of the cell cycle. This was associated with activation of AMPK, inhibition of the mTOR pathways and autophagy marker LC3B. However, metformin failed to suppress growth of xenografted tumors of Y79 human retinoblastoma cells in nu/nu mice, even when treated with a maximally tolerated dose level achieved in human patients. In conclusion, suprapharmacological levels (mM) of metformin, well above those tolerated in vivo, inhibited the proliferation of retinoblastoma cells in vitro. However, physiological levels of metformin, such as seen in the clinical setting, did not affect the growth of retinoblastoma cells in vitro or in vivo. This suggests that the potential beneficial effects of metformin seen in epidemiological studies may be limited to specific tumor types or be related to indirect effects/mechanisms not observed under acute laboratory conditions.
\end{abstract}

Correspondence to: Dr Demetrios G. Vavvas, Retina Service, Angiogenesis Laboratory, Massachusetts Eye and Ear Infirmary, Harvard Medical School, 243 Charles St., Boston, MA 02114, USA E-mail: vavvas@meei.harvard.edu

Key words: toxicity, autophagy, proliferation, apoptosis, cyclin

\section{Introduction}

Retinoblastoma is the most common primary malignant intraocular tumor in infants and children. In the United States, it affects 12 per million children aged $0-4$ years, representing $6.1 \%$ of all childhood cancers under the age of 5 years (1). Slightly more than half of the patients have the sporadic or non-inherited form of the disease, which results from the spontaneous inactivation of the retinoblastoma gene (RB1). Despite progress in the treatment of retinoblastoma, significant problems remain unsolved and metastatic disease is all too often fatal (2).

Although several treatment modalities are available for retinoblastoma, including local control of small to intermediate size tumors with laser and/or cryotherapy sometimes in combination with radiation and/or chemotherapy, or enucleation with or without systemic chemotherapy to control metastatic disease, each of them has major drawbacks, especially in pediatric patients. For example, conventional external beam radiation, which is used to control large tumors, has many complications, including an increased appearance of secondary malignancies, such as osteosarcoma. This complication occurs more frequently in patients with the hereditary-form of retinoblastoma. The 30 -year cumulative incidence of second malignancies is $>35 \%$ for patients who received external beam therapy vs. $6 \%$ for those patients without radiation (3). Intra-arterial chemiotherapy is currently novel treatment option for retinoblastoma, however, variables that affect blood flow can greatly affect drug delivery and therapy success (4-6). Also retinal and choroidal vasculopathy may occur in 10 to $20 \%$ of patients $(7,8)$. Studies show that direct intravitreal injection of melphalan may be effective in controlling active vitreous seeds, however, major concern is the potential for tumor dissemination (6,9-12). Systemic chemotherapy used as a first line treatment for intraocular retinoblastoma with subsequent consolidation with photocoagulation, cryotherapy or radiotherapy has a recurrence rate of $24 \%$ by 5 years (13). This increases to $50 \%$ for patients with vitreous seeds (14). Recent analyses by several research groups (15-18) show success for local control approaching 90-100\% for group A-C, but in less than 50\% for group D (new international classification). In addition, significant morbidity with the chemotherapy has been described previously (19). One 
of the drugs used for chemotherapy (etoposide) is thought to be associated with increased incidence of acute myeloblastic leukemia although the actual number of cases implicated so far has been low with just 20 cases reported in the literature (20). For these reasons, there is a pressing need for alternative treatment modalities for retinoblastoma with better safety and efficacy profiles.

Metformin is a biguanide drug that is widely used for the treatment of type II diabetes (4,21-23). A significant body of preclinical studies have shown that metformin decreases cancer cell viability and tumor growth in xenograft models $(6,11,24-28)$. However, other studies have shown that metformin in vivo may accelerate tumor growth. For example, BRAF-mutant melanoma cells that are resistant to metformin in vitro show accelerated growth in vivo when treated with metformin (29). Likewise, metformin/AMPK activation promoted an angiogenic phenotype in the $\mathrm{ER} \alpha$ negative MDA-MB-435 breast cancer model (30).

Some of the effects of metformin have been linked to activation of AMP-activated protein kinase (AMPK) in muscle, adipose and liver tissue $(22,31)$. AMPK is activated by cellular stress resulting in the restoration of energy levels through regulation of metabolism and growth (32-34). Insufficient AMPK activity allows uncontrolled cell growth despite the conditions of cellular stress (such as those occurring during tumorigenesis). Furthermore, metformin has been shown to inhibit the mTOR pathway and S6K1 phosphorylation implicated in protein synthesis $(4,6)$. Of note, these effects have been observed only at millimolar doses of metformin and recent studies indicate that metformin may exert its action through AMPK-independent mechanisms (6,11,24,28,35-41).

Thus the effects of metformin on the proliferation of cancer cells appear to be cell type dependent and not fully elucidated. For this reason, we investigated the effects of metformin on human retinoblastoma cancer cell lines in vitro and in vivo.

\section{Materials and methods}

Reagents. Metformin, MTT (3-(4,5-dimethylthiazol2-yl)-2,5-diphenyltetrazolium bromide) and ribonuclease-A were purchased from Sigma-Aldrich (St. Louis, MO, USA). Propidium iodide, calcein and DAPI were purchased from Invitrogen (Carlsbad, CA, USA). The following primary antibodies were purchased from Cell Signaling Technology (Danvers, MA, USA): phospho-ACC (Ser79), phospho-AMPK (Thr172), phospho-S6 ribosomal protein (Ser235/236), phospho-4E-BP1 (Thr37/46), p21 Waf1/Cip1, p27Kip1, LC3B, phospho-p38 MAPK (Thr180/Tyr182), phospho-Akt (S473), phospho-p44/42 MAPK (Erk1/2), $\beta$-tubulin, GAPDH. The following antibodies were purchased from Epitomics (Burlingame, CA, USA) cyclin E1, E2, D1, D3, A2, CDK4 and CDK2. Anti-Ki67 was purchased from Dako (Carpinteria, CA, USA), anti-CD31 and anti-CD11b from BD Bioscience (Franklin Lakes, NJ, USA).

Cell culture. The human retinoblastoma cells WERI and Y79 (ATCC, Manassas, VA, USA) were grown in RPMI-1640 medium (Invitrogen, Grand Island, NY, USA) supplemented with $15 \%$ fetal bovine serum (ATCC), penicillin and streptomycin (both at $100 \mu \mathrm{g} / \mathrm{ml}$; Invitrogen), $2 \mathrm{mM}$ L-glutamine
(Invitrogen) and $10 \mathrm{mM}$ HEPES (Invitrogen). Cells were incubated at $37^{\circ} \mathrm{C}$ in a humidified atmosphere of $95 \%$ air and $5 \% \mathrm{CO}_{2}$ and split when the cells reached approximately $80 \%$ confluence.

Trypan blue exclusion test, growth curve and doubling time. Retinoblastoma cells were seeded in 6-well plates at a concentration of $4.5 \times 10^{5}$ cells per well. On days 3, 6 and 9 cell number and viability was determined by trypan blue $(0.4 \%)$ dye exclusion and growth-inhibition curves were drawn. Experiments were performed in triplicate with 2 wells per condition.

Measurement of cell viability by the MTT assay. Cell viability was assessed by 3-(4,5-dimethylthiazol-2-yl)-2,5-diphenyltetrazolium bromide (MTT) assay. MTT assay is used to measure the reduction of a tetrazolium compound by the cellular mitochondria, producing an optically active soluble formazan.

Cells were cultured in 48-well plates at density 60,000 cells per well in $300 \mu \mathrm{l}$ growth medium. After 1 and 3 days of treatment with metformin, MTT $(5 \mathrm{mg} / \mathrm{ml}$ in PBS) was added to each well at a 1/10 volume. Cells were incubated for $1 \mathrm{~h}$ at $37^{\circ} \mathrm{C}$ and resuspended in DMSO. The absorbance at $595 \mathrm{~nm}$ was measured using a microplate reader. Data are displayed as percentage of control.

Flow cytometry assessment of cell viability. Live and dead cells were quantified using the fluorescent probes calcein AM and DAPI. Cells were cultured in 6-well plates at 500,000 cells per $2 \mathrm{ml}$ growth medium and were treated with $5 \mathrm{mM}$ metformin for $48 \mathrm{~h}$. The calcein was added at final concentration $0.1 \mu \mathrm{M}$ and DAPI at $3 \mu \mathrm{M}$. The samples were read on Becton Dickinson FACScan. Results were analyzed with Summit 4.3 software.

Flow cytometry assessment of the cell cycle. Cellular DNA content was assessed by flow cytometry. Cells were seeded in 6 -well plates at density 500,000 cells per $2 \mathrm{ml}$ growth medium and were treated with $5 \mathrm{mM}$ metformin for $48 \mathrm{~h}$. After overnight fixation in $75 \%$ ethanol, cells were suspended in PBS with DNase-free RNase A at final concentration $0.3 \mathrm{mg} / \mathrm{ml}$ and propidium iodide at final concentration $1 \mathrm{mg} / \mathrm{ml}$. DNA content assessed on Becton Dickinson LSRII flow cytometer. Results were analyzed with Modfit LF software.

Protein extraction and western blot analysis. For in vitro experiments, cells were incubated for $48 \mathrm{~h}$ in the presence or absence of metformin at various concentrations $(12 \mu \mathrm{M}$ to $10 \mathrm{mM}$ ). For in vivo experiments, tumor pieces were cut. The samples lysed in M-PER Mammalian Protein Extraction Reagent (Thermo-Scientific, Pierce Protein Research Products) with protease (according to manufacturer's suggestions; Roche Applied Science) and phosphatase inhibitor cocktails (dilution 1:50; Thermo-Scientific, Pierce Protein Research Products). Total amount of protein $(10 \mu \mathrm{g})$ was loaded onto a 4-12\% Bis-Tris Gel (NuPAGE; Invitrogen). The electrophoresis was done using NuPAGE MOPS Running Buffer (Invitrogen) and then samples were transferred onto a PVDF membrane (Millipore, Billerica, MA, USA). The membranes were blocked for $45 \mathrm{~min}$ at room temperature in $5 \% \mathrm{wt} / \mathrm{vol}$ BSA, $1 \mathrm{X}$ TBS $0.1 \%$ Tween-20. The primary antibodies were 
A
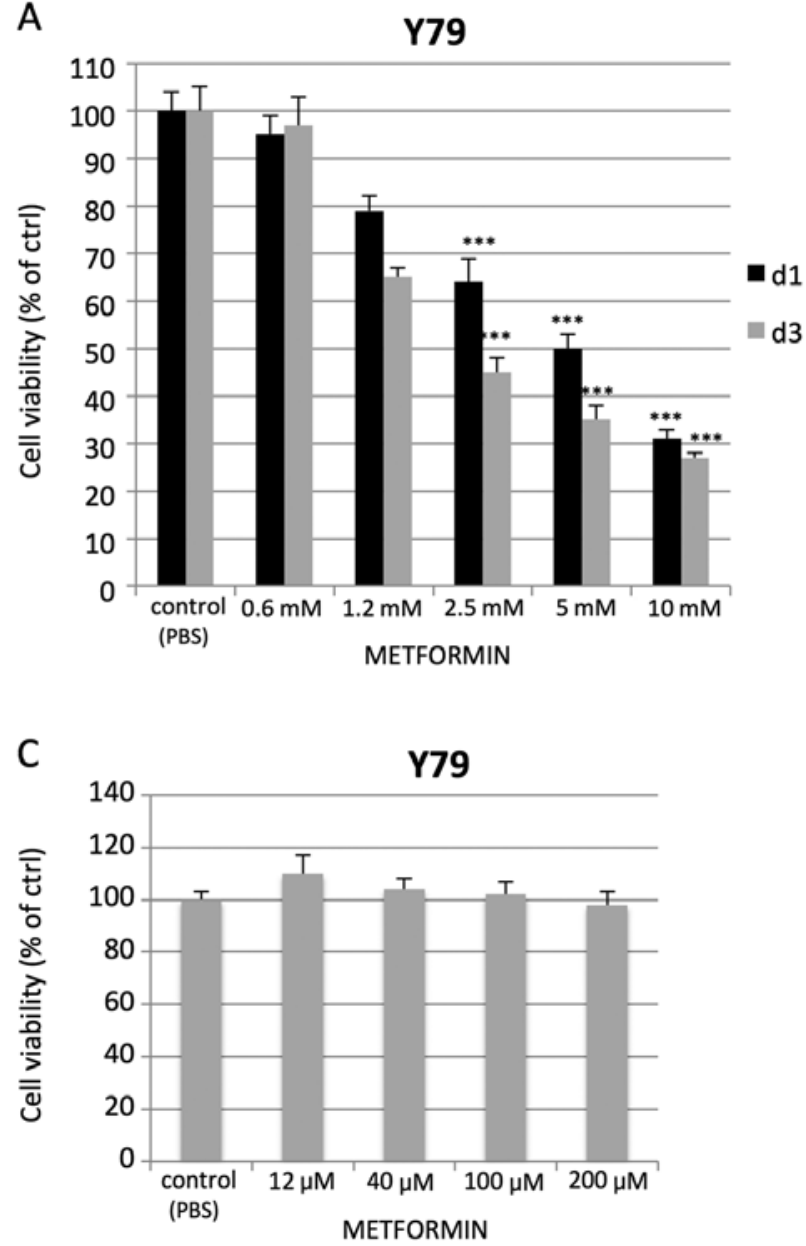

B

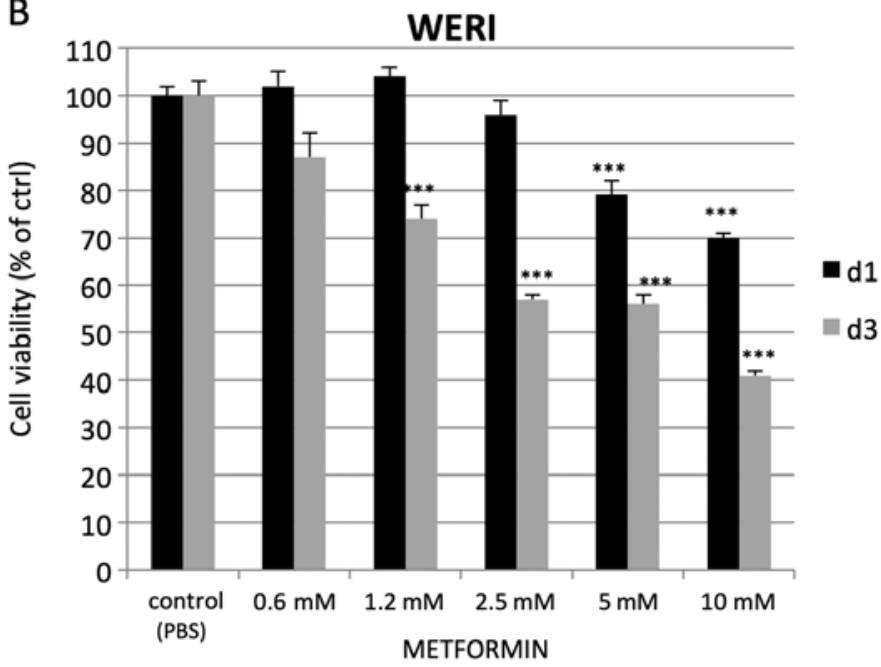

D

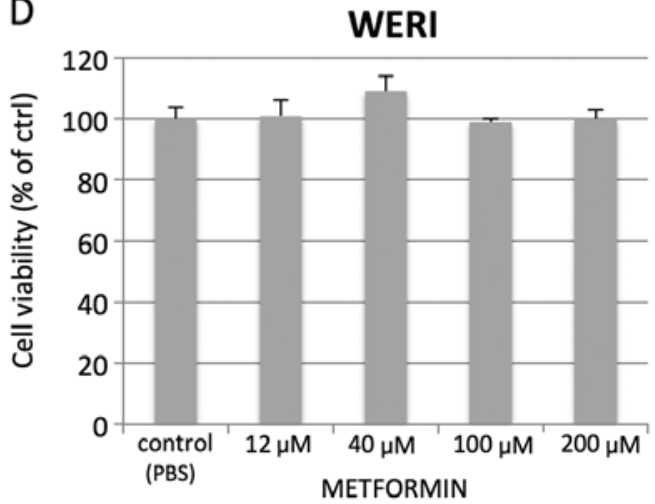

Figure 1. Metformin inhibits the proliferation of the retinoblastoma cells at mM, but not $\mu \mathrm{M}$ levels as measured by MTT. Retinoblastoma cell lines WERI and Y79 were treated with concentrations of metformin (12 $\mu \mathrm{M}$ to $10 \mathrm{mM})$ and cell viability was measured by MTT assay. (A-D) mM but not $\mu \mathrm{M}$ levels caused proliferation inhibition of both cell lines. The results are expressed as percentage of growth (\%) relative to control values and are average of three independent experiments. Data are presented as mean $\pm \operatorname{SEM}(\mathrm{n}=12) ;{ }^{* *} \mathrm{p}<0.01,{ }^{* * *} \mathrm{p}<0.005 ; \mathrm{d} 1$, day 1 ; d3, day 3 .

diluted in 5\% wt/vol BSA 1X TBS, 0.1\% Tween-20 1:1,000 for all except CCNE1, E2, D1, D3, A2, CDK4 and CDK2 which were used at concentrations 1:5,000. After overnight incubation at $4^{\circ} \mathrm{C}$, the membranes were washed three times $1 \mathrm{X}$ TBS $0.1 \%$ Tween-20 and incubated for $45 \mathrm{~min}$ at room temperature with the horseradish peroxidase-labeled secondary anti-rabbit antibody at 1:50,000 (Jackson Immuno Research, West Grove, PA, USA). The immunoreactive bands were visualized with ECL exposured to Fuji RX film (Fujifilm, Tokyo, Japan). The results were quantified using ImageJ software.

Animals. All animal experiments complied with guidelines established by the Association for Research in Vision and Ophthalmology for the use of animals in ophthalmic and vision research, and were approved by the Animal Care and Use Committee of the Massachusetts Eye and Ear Infirmary (Boston, MA, USA). Four to five-weeks-old BALB/c (nu/nu) female mice were purchased from Charles River Laboratories (MA) and maintained in a facility under specific pathogen-free conditions in a climate controlled room with a $12 \mathrm{~h}$ light/dark cycle.

Xenograft tumor growth assay. Xenograft tumors were established bilaterally in nu/nu mice by means of a single subcutaneous injection in each flank consisting of 4 million Y79 retinoblastoma cells suspended in $0.3 \mathrm{ml}$ of a $1: 1$ mixture of ice-cold matrigel basement membrane matrix (BD Bioscience, MA, USA) and RPMI-1640 medium. Once a tumor mass became visible (within the week from injection of the cells), mice were randomly assigned to receive either daily peritoneal injections of metformin $(250 \mathrm{mg} / \mathrm{kg})$ or normal saline for 31 days. Two independent experiments were performed with five mice assigned to each group. The dose was based on the LD50 of metformin $(420 \mathrm{mg} / \mathrm{kg})$, as well as on human therapeutic and maximum prescribed doses for human patients $(2,000-2,500 \mathrm{mg} /$ day $)(6,11)$. The tumor volume was monitored by external measurement in two dimensions with calipers every week and determined according to the equation: volume $\left(\mathrm{mm}^{3}\right)=4 / 3 \times$ phi $\times\left(\right.$ length/2) $\times(\text { width/2) })^{2}(9)$. Mice were weighted once a week.

Immunohistochemistry assay and pathological evaluation. Five tumors from each group were frozen, cut into $10 \mu \mathrm{m}$ sections and analyzed for retinoblastoma cell proliferation, vessel area and macrophage infiltration. Cryosections were also used for immunohistochemistry, first being fixed in $4 \%$ paraformaldehyde, blocked with $5 \%$ goat serum, and 
A

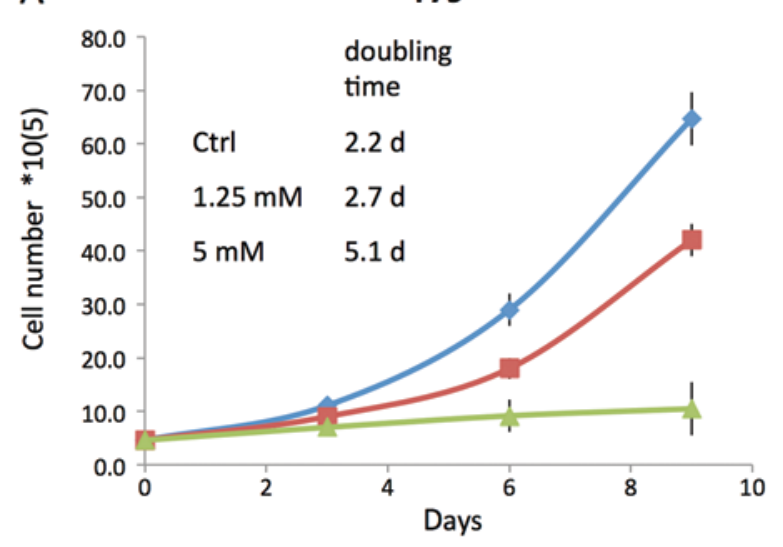

C

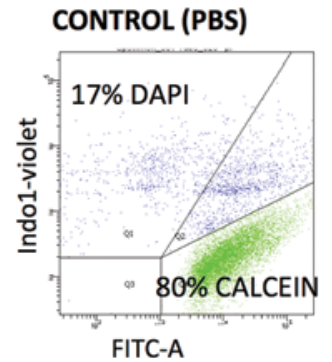

E

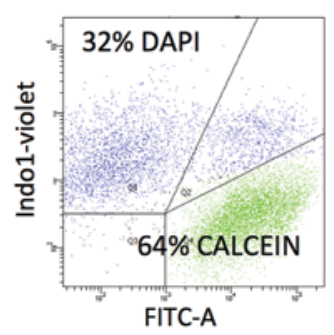

B

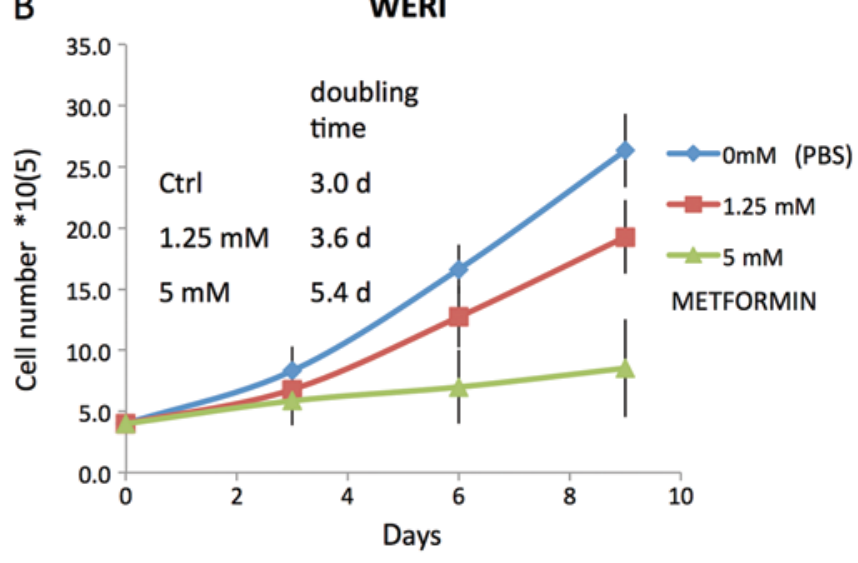

D

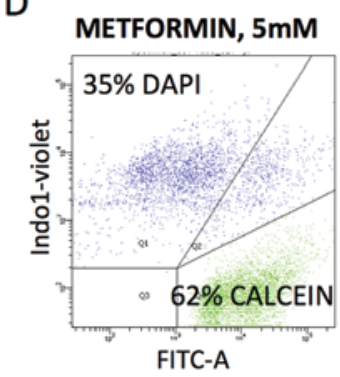

F

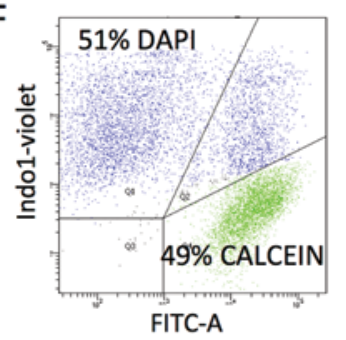

Figure 2. Metformin at higher mM levels increases the doubling time and causes cell death of retinoblastoma cells. (A and B) Retinoblastoma cell lines WERI and Y79 were treated with 1.25 and $5 \mathrm{mM}$ of metformin for $48 \mathrm{~h}$. Trypan blue exclusion test was performed on days 3, 6 and 9 ; metformin at mM levels caused proliferation inhibition; doubling time increased proportionally to metformin dose. The results are the average of three independent experiments. (C-F) The retinoblastoma cell lines Y79 and WERI were treated for $48 \mathrm{~h}$ with $5 \mathrm{mM}$ of metformin, and cell viability and death was measured by calcein AM and DAPI staining using FACS; comparing to control, mM levels of metformin cause increased cell death and decreased viability (** $\mathrm{p}<0.01$ for WERI and ${ }^{* * *} \mathrm{p}<0.001$ for $\left.\mathrm{Y} 79\right)$. The data are representative of three independent experiments $(\mathrm{n}=12)$.

permeabilized with $0.1 \%$ Triton X-100. The sections were incubated in a humid chamber with primary antibodies, including anti-Ki67 (1:100), anti-CD31 (1:100) and anti-CD11b (1:100). A fluorophore-conjugated secondary antibody (Molecular Probes, Carlsbad, CA, USA) was used to detect fluorescence using a confocal microscope (Leica Microsystems, Wetzler, Germany). Nuclei were stained with DAPI. Cryostat sections were examined at random fields at $\times 20$ magnification and the percentage of fluorescent-positive cells/DAPI-positive cells in each field was measured. Tumor vessel area was calculated as the number of image pixels that stained positive for CD31 per high-power field.

TUNEL assay in tissue sections. Frozen $10 \mu \mathrm{m}$ sections were prepared from tumors as above and stained with TUNEL cell death detection kit (Roche Diagnostics Corp., Indianapolis, IN, USA) according to the manufacturer's recommendations. Sections were counter stained with DAPI and examined under an epifluorescent microscope (Leica Microsystems, Wetzler,
Germany). Cryostat sections were examined at random fields at $\times 20$ magnification and the percentage of TUNEL-positive cells/DAPI-positive cells in each field was measured.

Serum levels of metformin, insulin-like growth factor-1 (IGF-1) and insulin-like growth factor binding protein 3 (IGFBP-3). Retro-orbital blood was collected 3 and $15 \mathrm{~h}$ after metformin injection for ELISA testing and metformin levels assessment from all mice after euthanization. The samples were mixed with $4 \mathrm{mM}$ EDTA and left at $4^{\circ} \mathrm{C}$ for $2 \mathrm{~h}$, then centrifuged for $15 \mathrm{~min}$ at $180 \mathrm{x} \mathrm{g}$. Serum levels of IGF-1 and IGFBP-3 were measured using a Mouse/Rat IGF-I and IGFBP-3 ELISA kit (R\&D Systems, Minneapolis, MN, USA). Metformin levels were assayed ( 3 and $15 \mathrm{~h}$ after i.p. metformin injection), using high-performance liquid chromatography (NMS Lab, Willow Grove, PA, USA).

Statistical analysis. The data are expressed as mean \pm standard error of the mean (SEM). Statistical significance was 
A

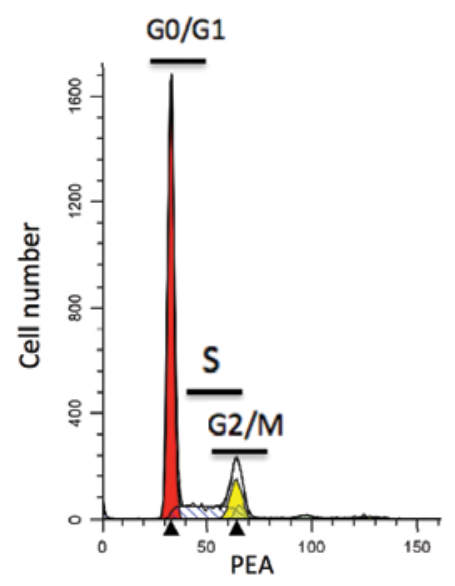

B

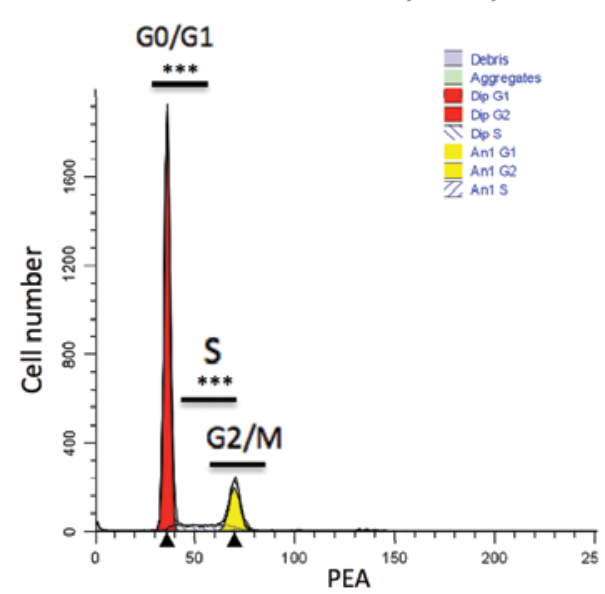

C
D

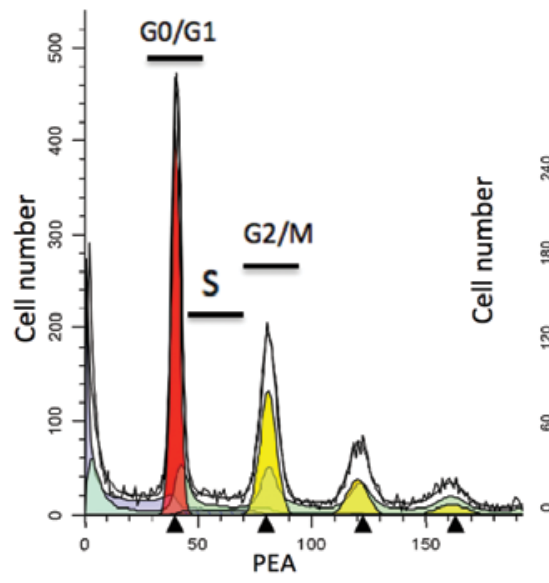

$\mathrm{E}$

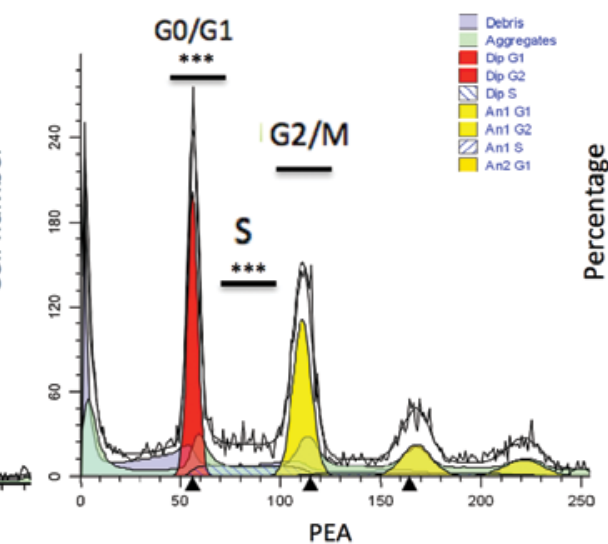

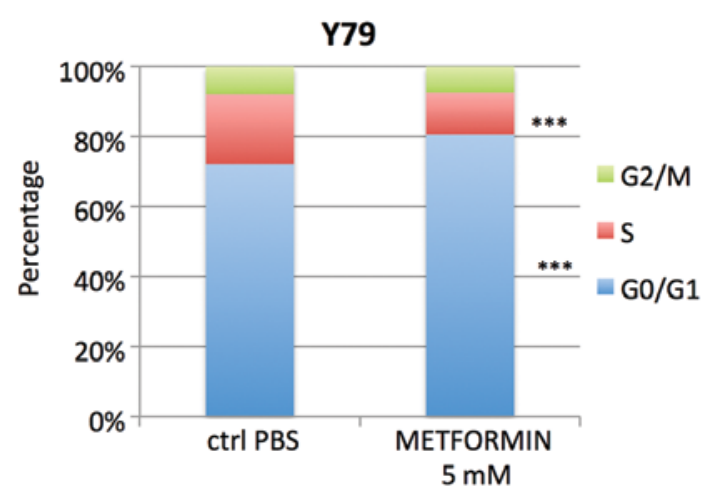

Figure 3. Metformin effects on the cell cycle in human retinoblastoma cells. Y79 retinoblastoma cells and WERI cells were treated with 5 mM metformin for 48 h. (A-C) Metformin caused cell cycle arrest in G0/G1 phase for Y79 while decreasing cell number in S phase. (D-F) Metformin caused cell cycle arrest in S phase for WERI cells while decreasing cell number in G0/G1 phase. All the data are graphically represented as percentage of cells in G0/G1 phase, $\mathrm{S}$ phase, G2/M phase. The data are representative of three independent experiments $(\mathrm{n}=12){ }^{*}{ }^{* * *} \mathrm{p}<0.001$.

evaluated using the one-way ANOVA test with Dunnett's modification for multiple means comparison or t-test for two means. * $\mathrm{p}<0.05$ was considered statistically significant. Two-tailed tests were used for all comparisons.

\section{Results}

Metformin inhibits the growth and increases doubling time of human retinoblastoma cells in vitro at $m M$, but not $\mu M$ levels. In order to determine whether metformin affects human retinoblastoma cell viability and proliferation, we analyzed the effect of the drug on two human retinoblastoma cell lines: WERI and Y79. Cells were treated with various concentrations of metformin $(12 \mu \mathrm{M}$ up to $10 \mathrm{mM})$ and the viability was assed by the MTT assay. Increasing doses of metformin led to a corresponding reduction in cell viability but at doses in the $\mathrm{mM}$ range of concentrations (Fig. 1A and B). Reduced viability was not observed at $\mu \mathrm{M}$ concentrations (Fig. 1C and D). Assessment of cell growth and doubling time by trypan blue exclusion showed decreased growth rates in the presence of $\mathrm{mM}$ levels of metformin. Doubling time increased from 2.2 to 5.1 days for the Y79 cell line and from 3 to 5.4 days for the WERI cell line (Fig. 2A and B). Metformin treatment at $5 \mathrm{mM}$ also increased the proportion of non-viable cells and decreased the proportion of viable cells (Fig. 2D and F) as judged by calcein AM/DAPI flow cytometry when compared to control (Fig. 2C and E).

Metformin at higher mM levels leads to variable cell cycle changes in human retinoblastoma cells and to a global reduction in cell cycle regulators. Previous reports have shown arrest in G0/G1 or S phase by mM levels of metformin (32). In our study, cell cycle analysis revealed that metformin treatment $(5 \mathrm{mM}$ for $48 \mathrm{~h}$ ) of Y79 cells led to a statistically significant increase in cells in $\mathrm{G} 0 / \mathrm{G} 1$ phase $(72$ to $81 \%, \mathrm{p}<0.001)$, and a decrease in $\mathrm{S}$ phase (20 to $12 \%, \mathrm{p}<0.001$ ) (Fig. 3A-C). In contrast the reverse was seen when WERI were treated with metformin. There was a decrease in $\mathrm{G} 0 / \mathrm{G} 1$ phase (83 to $73 \%, \mathrm{p}<0.001)$ and an increase in cells in S phase (9 to 19\%, p<0.001) (Fig. 3D-F). These cell cycle effects were not associated with specific cyclin and CDK changes but rather they were associated with non-specific global reduction in cyclins. For Y79 cell line on treatment with metformin we noted decrease of cyclin D3, E1, E2, A2 (Fig. 4B-E), cyclin dependent 
Y79

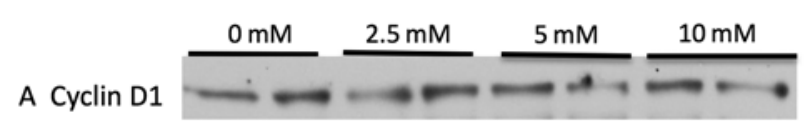

B Cyclin D3

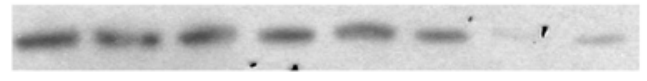

C Cyclin E1

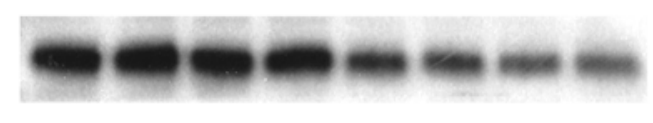

D Cyclin E2

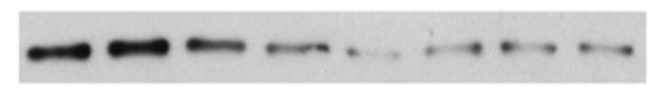

E Cyclin A2 $-\infty-\cdots-\cdots$

F CDK2

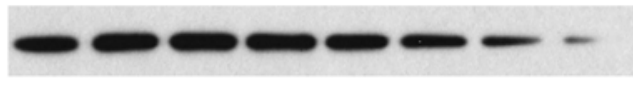

G CDK4

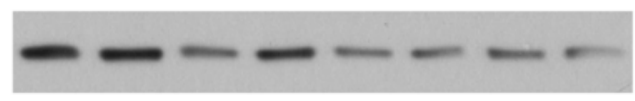

tubulin

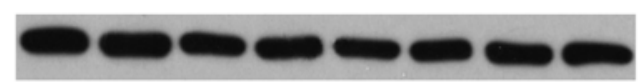

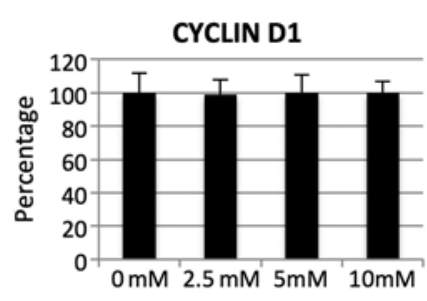
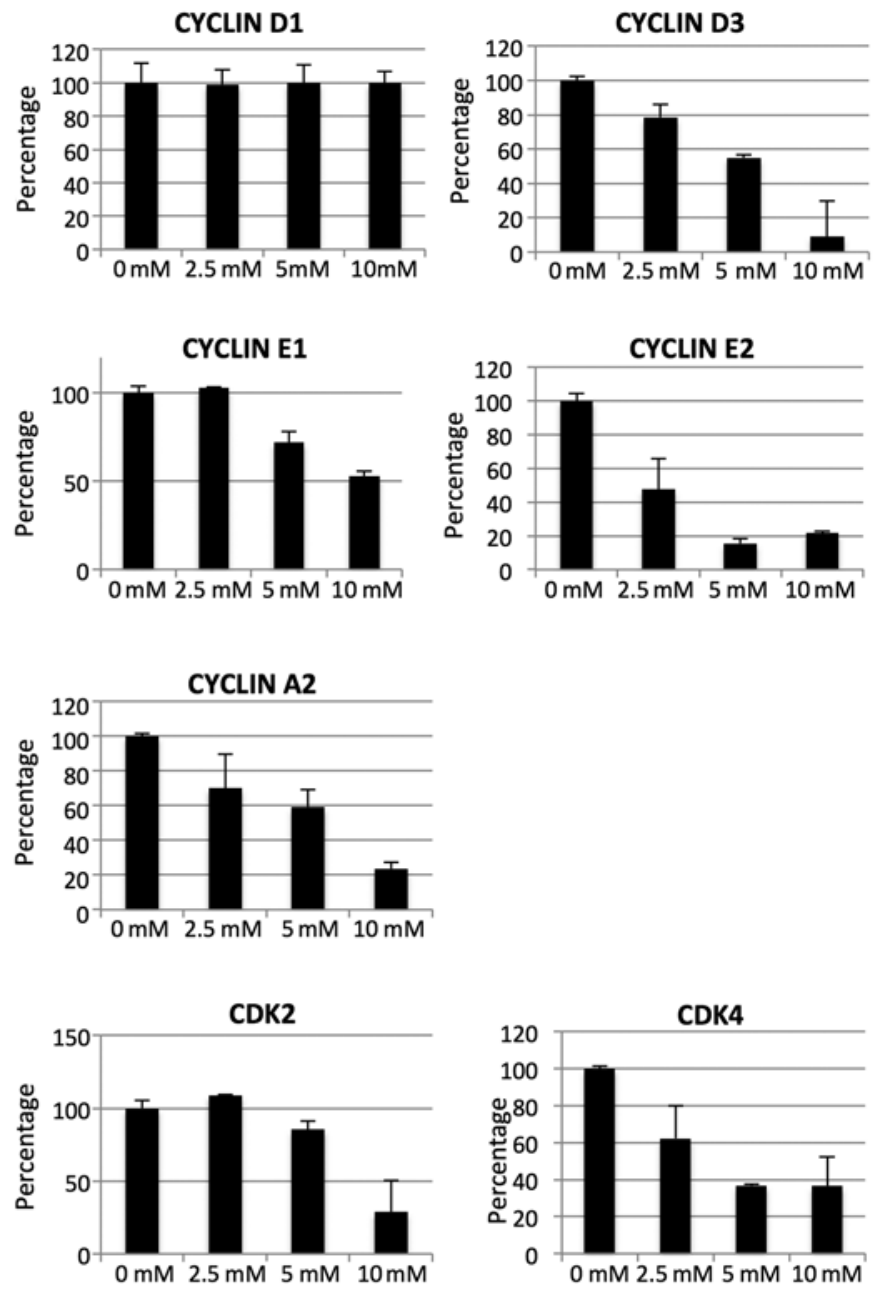

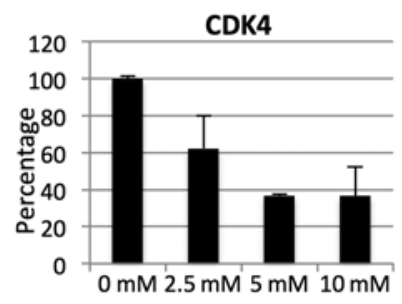

Figure 4. Metformin effect on cyclins D, E, A and Cdk2 and 4 in Y79 retinoblastoma cells. (A-G) Y79 cells were treated with 2.5, 5 and $10 \mathrm{mM}$ metformin for $48 \mathrm{~h}$ and subjected to western blot analysis. Metformin caused downregulation of the cyclines D, E, A and CDK2 and 4 except cycline D1 for Y79. Data are representative of two independent experiments. Density values of the bands are graphically expressed relative to control. Data are shown as mean \pm SEM $(n=4)$.

kinases CDK2 and CDK4 (Fig. 4F and G). Levels of cyclin D1 were not decreased for Y79 (Fig. 1A). For WERI cell line on treatment with metformin we noted decrease of cyclin D1, D3, E1, E2, A2 (Fig. 5A-E) as well as CDK2 and CDK4 (Fig. 5F and $\mathrm{G}$ ). In addition, metformin treatment reduced CDK inhibitors p21 (Fig. 6A and E) and p27 (Fig. 6B and F) in both cell lines. Metformin reduced levels of positive cell growth regulators, such as phospho-p44/42 MAPK in Y79 (Fig. 6C) and WERI (Fig. 6G). Other cell proliferation and survival factors, such as phospho-Akt were unchanged in the Y79 cell line (Fig. 6D) but were found to be activated in the WERI cell line (Fig. 6H), suggesting that some of the effects of metformin on cell cycle may be non-specific.

Metformin at higher mM levels inhibits the mTOR pathway, upregulates phospho-p38MAPK, autophagy marker LC3B and activates $A M P K$. Autophagy is usually activated under conditions of cell stress and is inhibited by the mTOR pathway, an intracellular signaling pathway important in apoptosis. Indeed $\mathrm{mM}$ levels of metformin decreased the mTOR pathway as judged by phosphorylation of S6RP (Fig. 7A and E) and 4E-BP1 (Fig. 7B and F) and led to variable increases in
LC3B-I and LC3B-II protein levels (Fig. 7C and G). Similar to some $(35,37,38)$ but not other studies $(39,40)$ the induction of LC3 was associated with increases in p38 MAPK (Fig. 7D and $\mathrm{H}$ ). Similar to other investigators (21) we found AMPK to be activated in retinoblastoma cells at the $\mathrm{mM}$ level as determined by phospho-ACC (Fig. 8A and B).

Metformin at pharmacologic levels fails to suppress growth of human retinoblastoma xenografts in vivo. In order to evaluate the in vivo effect of metformin on retinoblastoma growth, heterotopic tumor xenografts of human Y79 retinoblastoma cells were established and mice were treated with metformin $(250 \mathrm{mg} / \mathrm{kg}$ every $24 \mathrm{~h})$ or equal volume of normal saline delivered i.p. (intraperitoneally). The dose of metformin was based on previous studies $(11,28)$ and the LD50 for mice $(420 \mathrm{mg} / \mathrm{kg})$, as well as on the typical therapeutic and maximally prescribed human doses $(2,000-2,500 \mathrm{mg} /$ day $)(6,11)$.

In our in vivo experiments, metformin levels in mouse sera were on average 2.13 and $0.66 \mu \mathrm{g} / \mathrm{ml}$ for peak and trough, respectively (measured via high-performance liquid chromatography). The level of $2.13 \mu \mathrm{g} / \mathrm{ml}$ metformin equals about $12 \mu \mathrm{M}$. For comparison human peak levels are $1.03( \pm 0.33)$, 

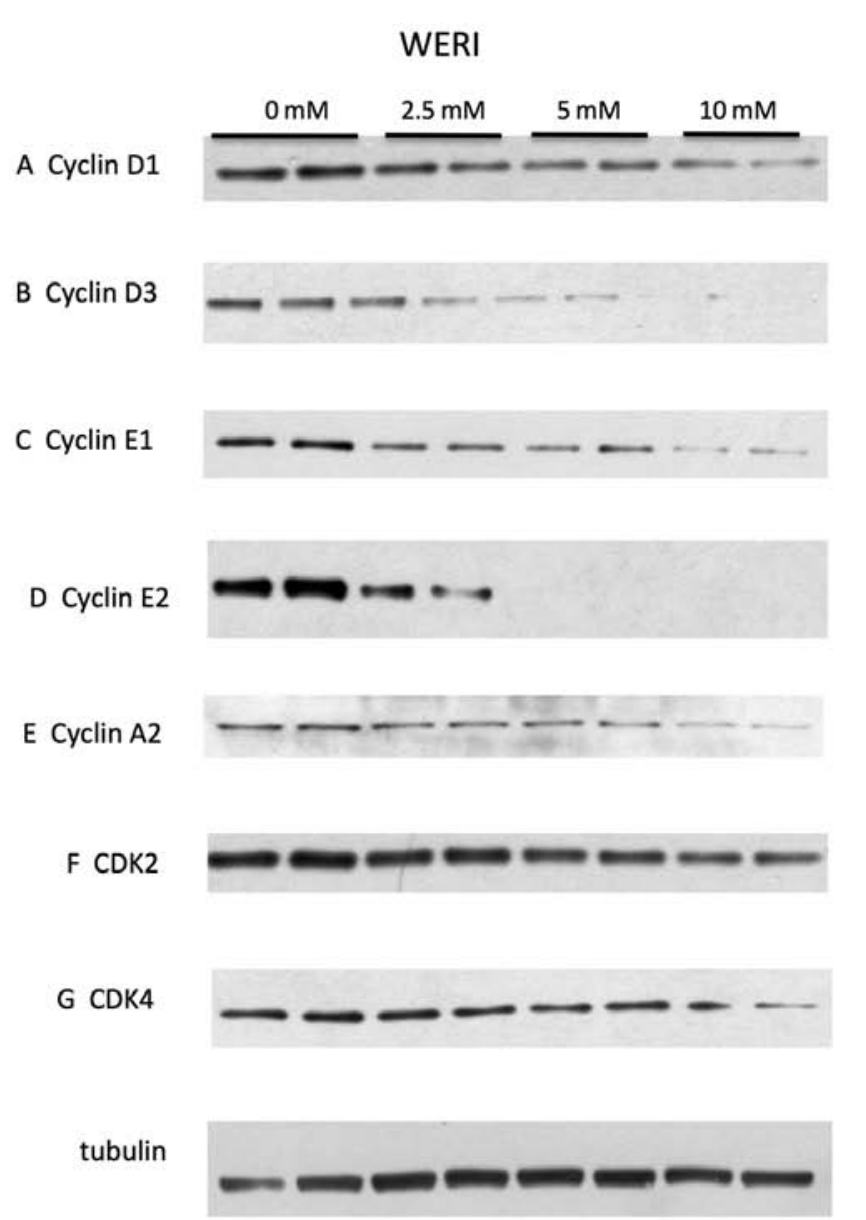
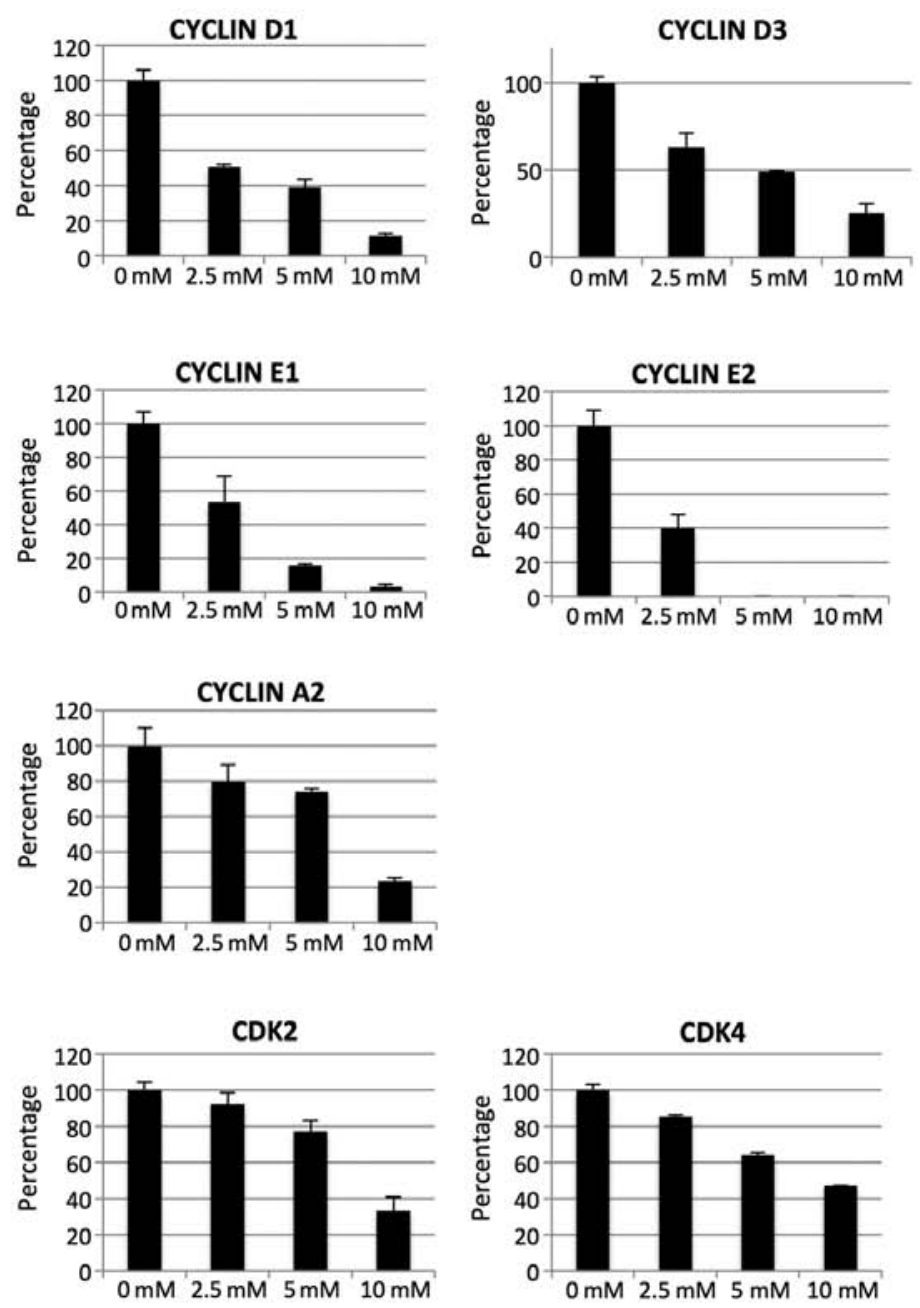

Figure 5. Metformin effects on cyclins D,E, A and Cdk2 and 4 in WERI retinoblastoma cells. (A-G) WERI cells were treated with $2.5,5$ and $10 \mathrm{mM}$ metformin for $48 \mathrm{~h}$ and subjected to western blot analysis. Metformin caused downregulation of all cyclines D, E, A and CDK2 and 4. Data are representative of two independent experiments. Density values of the bands are graphically expressed relative to control. Data are shown as mean \pm SEM $(n=4)$.

$1.60( \pm 0.38), 2.01( \pm 0.42)$ for $500 \mathrm{mg}$ p.o. (orally) daily, $850 \mathrm{mg}$ p.o. daily or $850 \mathrm{mg}$ p.o. taken three times per day, respectively (42). Despite achieving equivalent pharmacologic levels of metformin in mice, tumor growth was not significantly different than in the vehicle treated animals (Fig. 9A-C). The mean tumor weight, determined at necropsy, in the control mice was $0.98 \mathrm{~g}$, as compared to $0.82 \mathrm{~g}$ in the metformin-treated mice ( $\mathrm{p}=0.89, \mathrm{n}=10$, two independent experiments; Fig. 9D). The body weight of the tumor-injected mice was not found to differ significantly from controls (Fig. 9E).

We observed that metformin 3 and $15 \mathrm{~h}$ after i.p. administration did not affect proteins/pathways in vivo thought to be affected by metformin at $\mathrm{mM}$ levels in vitro such as AMPK, phospho-ACC, mTOR, p21 (Fig. 10A-E). Also the drug did not significantly affect the IGF1, IGFBP3 or the IGF1/IGFBP3 ratio in our experiments (Fig. 10F-H). When tumors were examined histologically significant changes of Ki-67 proliferative index [Ki67(+) cells/DAPI(+) cells; Fig. 11A-C] were not observed. Apoptosis labeling was similar in both groups [TUNEL(+) cells/DAPI(+) cells; Fig. 11D-F]. On treatment with metformin we observed a small, nonsignificant decrease in tumor vascularity (vessel area: $\mu \mathrm{m}^{2} / \mathrm{hpf}$; Fig. 12A-C) and a small, nonsignificant decrease of infiltration by CD11b cells [CD11b(+) cells/DAPI(+) cells Fig. 12D-F].

\section{Discussion}

Metformin, a drug used primarily for the treatment of type II diabetes, has been reported in epidemiological studies to reduce the incidence of certain cancers among diabetic patients (43). Initial studies examining the anti-proliferative effects of metformin have focused on tissues involved in insulin signaling and glucose/fatty acid metabolism, such as muscle and liver $(4,21,23)$. However, the effects of metformin on other tissues or cells in culture have not been well characterized. Of the studies available $(6,11,28)$, the anticancer effects of metformin are reportedly seen at $\mathrm{mM}$ levels, levels that are 100-1,000 times in excess of doses capable of being achieved by pharmacotherapy with metformin in humans. In addition, some conflicting data have arisen in in vitro and in vivo studies, with most indicating that the drug may have the potential to directly suppress tumor growth $(11,24,28,32,44)$, while other reports indicate that metformin may not halt the growth of tumors $(25,29,45,46)$. Increased tissue accumulation of metformin relative to blood levels have been 


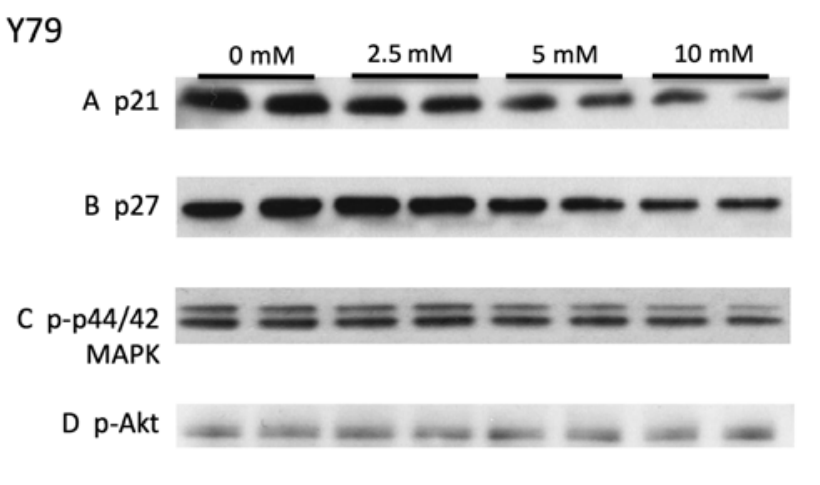

tubulin
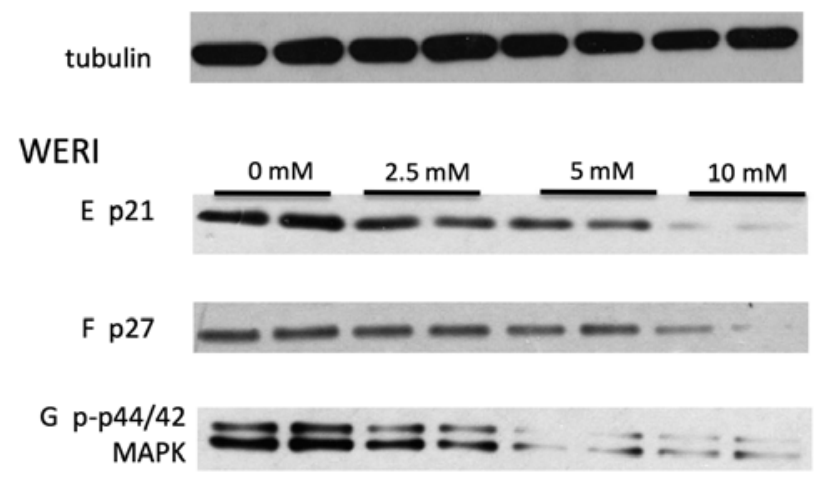

H p-Akt

tubulin
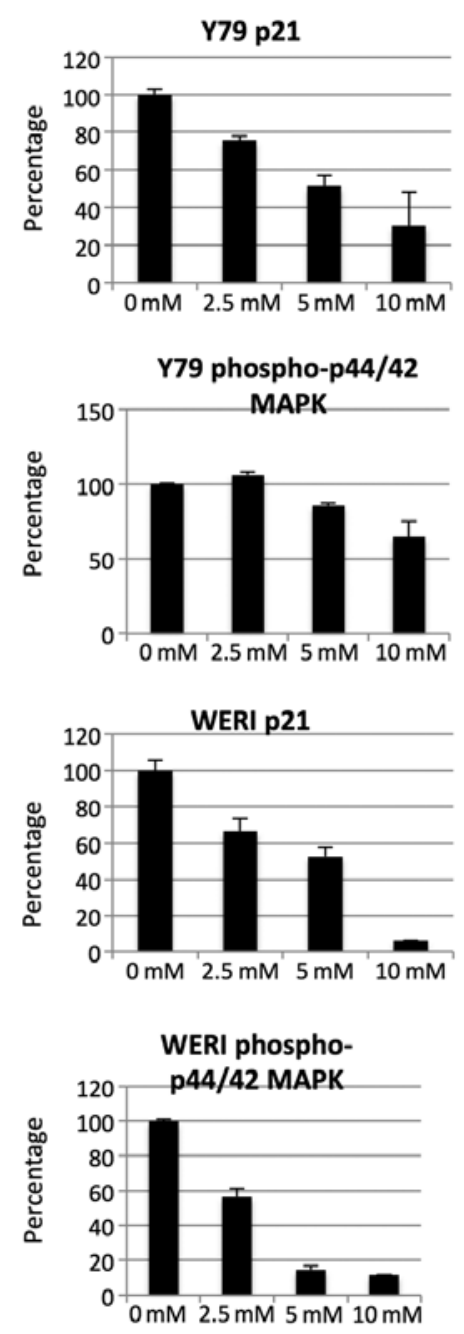
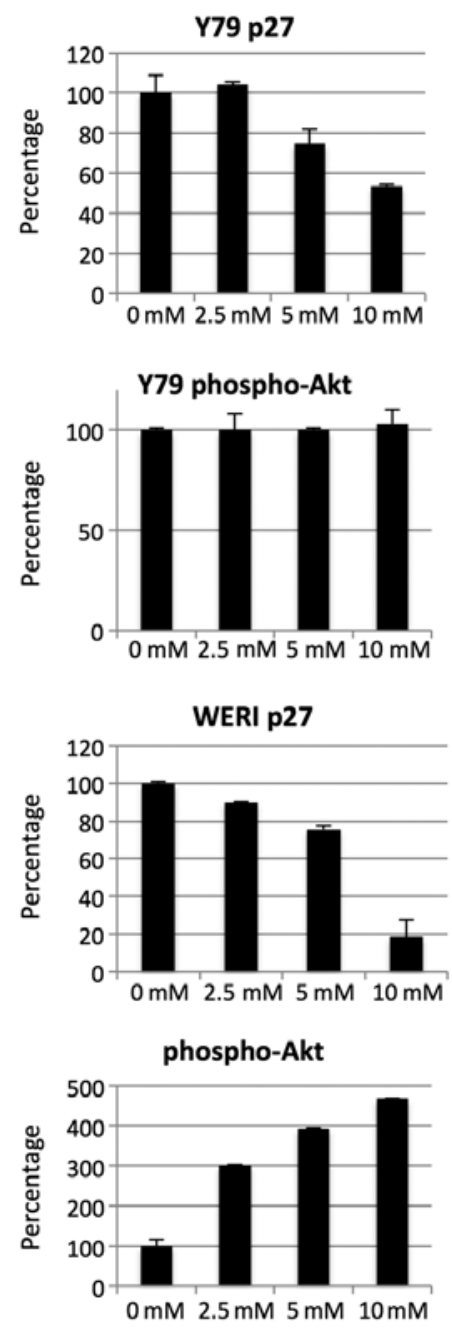

Figure 6. Metformin effects on the cell cycle regulators p21, p27 phospho-p44/42MAPK and phospho-Akt in Y79 and WERI cell lines. (A-D) Y79 cells were treated with $2.5,5$ and $10 \mathrm{mM}$ metformin for $48 \mathrm{~h}$ and subjected to western blot analysis. Metformin caused downregulation of p21, p27, phosphop44/42MAPK while it did not affect Akt. (E-H) WERI cells were treated with 2.5, 5 and $10 \mathrm{mM}$ metformin for $48 \mathrm{~h}$ and subjected to western blot analysis. Metformin caused downregulation of p21, p27, phospho-p44/42MAPK while it upregulated Akt. Data are representative of two independent experiments. Density values of the bands are graphically expressed relative to control. Data are shown as mean \pm SEM $(n=4)$.

hypothesized to explain metformin anticancer activity in vivo, although the concentration seen in most tissues still remains at the low $100 \mu \mathrm{M}$ level (47). Other explanations proposed relate to metformin's well-known effects on cholesterol, leptin, insulin levels and adiponectin, suggesting that some metabolic changes account for a reduction in tumor growth.

Some retrospective epidemiologic studies have revealed a decrease in the incidence of certain cancers in patients treated with metformin (48-50). The most recent meta-analysis suggests that metformin reduces the risk for colorectal cancer and hepatocellular cancer, but not for pancreatic, breast, gastric, prostate, bladder or lung cancer (50). Other case-control trials indicate that taking metformin is not associated with altered risk for esophagus cancer (51), endometrial cancer (52), lung cancer (53), colorectal cancer (54), prostate cancer recurrence and related mortality (55). Some trails suggest that metformin is associated with a decreased risk of pancreatic cancer but in women only (56). Others indicate that although metformin decreases risk of lung cancer, diabetics who develop lung cancer while receiving metformin may have a more aggressive cancer phenotype (57). Some trials show that only long-term use of metformin is associated with a tendency towards a decreased risk of ovarian cancer (58). Similarly long-term use of metformin ( $>5$ years) but not short-term use was associated with lower risk for developing breast cancer compared with no use of metformin (59).

In this study, we examined the effects of metformin on human retinoblastoma growth in vivo, as well as in vitro, ranging from $\mathrm{mM}$ down to $\mu \mathrm{M}$ concentrations. We show that metformin inhibition of retinoblastoma cells in vitro, like all other cancer-related studies involving metformin, is seen at $\mathrm{mM}$ levels. Furthermore, levels similar to therapeutic levels achieved in humans $(\mu \mathrm{M})$ do not have an impact on retinoblastoma growth either in vitro or in vivo.

High dose metformin has been shown to increase the activity of AMPK in various cell lines at $\mathrm{mM}$ levels similar to those used in our study $(6,24,27,31,32,60)$ and activation of AMPK has been shown to be involved in cell proliferation $(61,62)$. AMPK activation leads to inhibition of the mTOR pathway through tuberous sclerosis complex 2 (TSC2) (63) or 
Y79

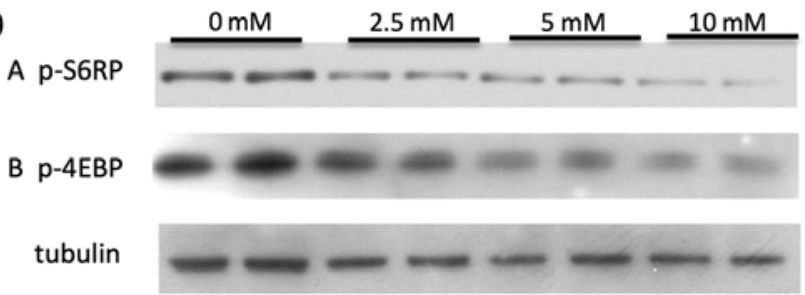

C LC3B

D p-p38MAPK

tubulin

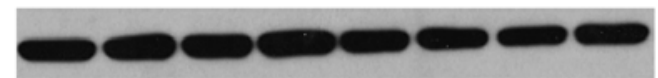

WERI

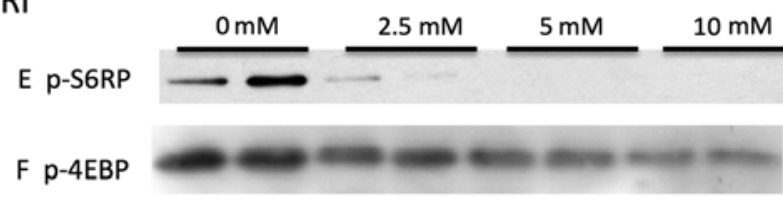

tubulin

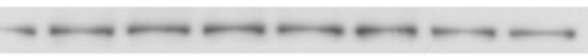

G LC3B

H p-p38MAPK

tubulin

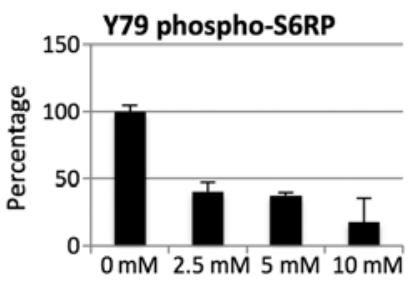

Y79 phospho-4EBP
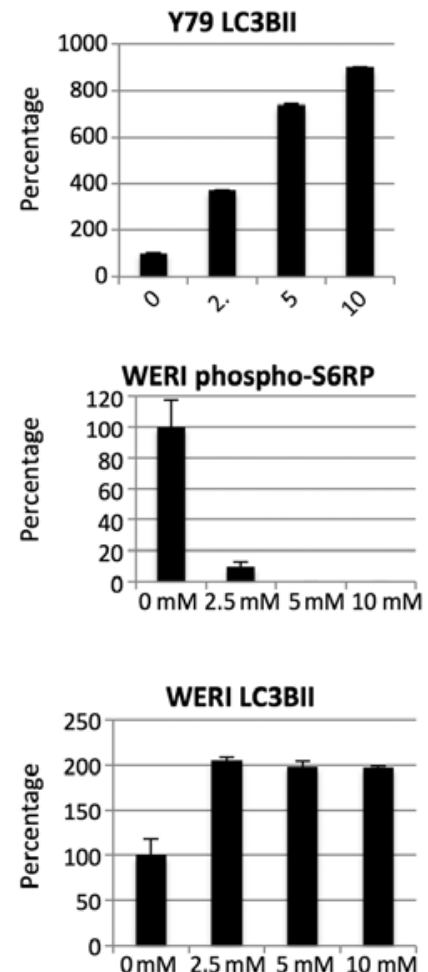
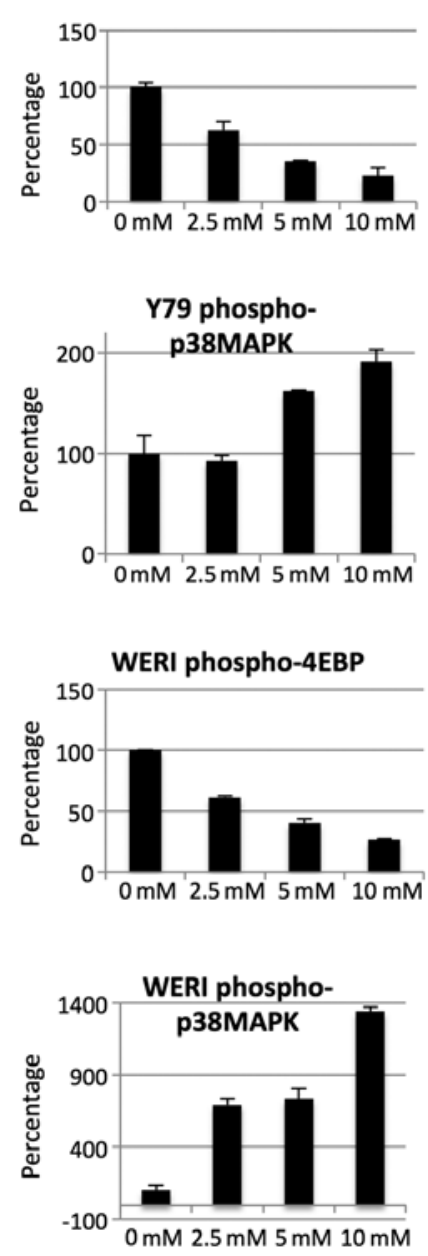

Figure 7. Metformin effects on phospho-p38MAPK, autophagy and the mTOR pathway in Y79 and WERI cell lines. (A-D) Y79 cells were treated with 2.5, 5 and $10 \mathrm{mM}$ metformin for $48 \mathrm{~h}$ and subjected to western blot analysis. Metformin caused downregulation of p-S6RP, p-4EBP while it caused upregulation of LC3B I and II and upregulation of phospho-p38MAPK. (E-H) WERI cells were treated with 2.5, 5 and $10 \mathrm{mM}$ metformin for $48 \mathrm{~h}$ and subjected to western blot analysis. Metformin caused downregulation of p-S6RP, p-4EBP while it caused upregulation of LC3B I and II and upregulation of phospho-p38MAPK. Data are representative of two independent experiments. Density values of the bands are graphically expressed relative to control. Data are shown as mean $\pm \operatorname{SEM}(\mathrm{n}=4)$.

A
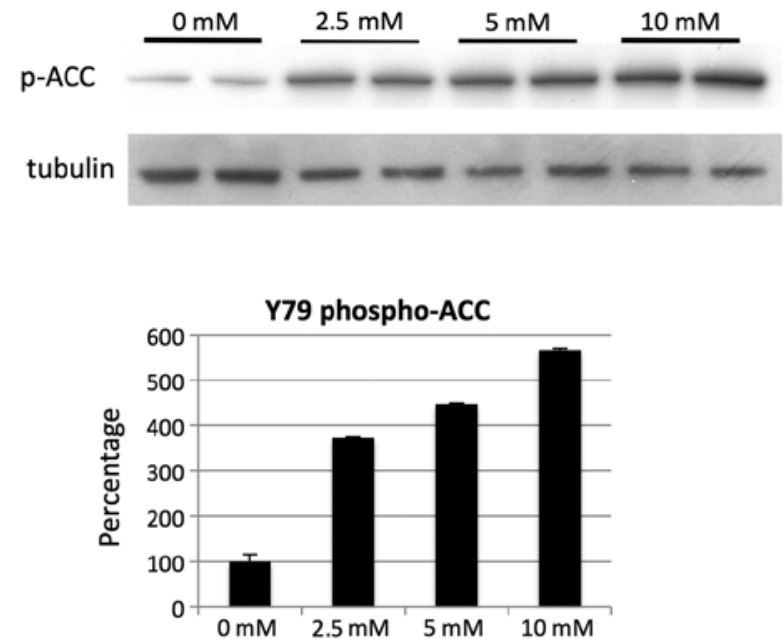

B

WERI

p-ACC

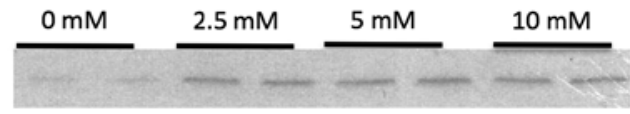

tubulin

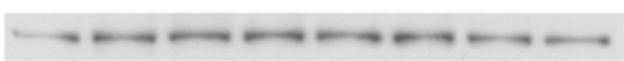

Figure 8. Metformin activates AMPK as judged by increase of phosphorylation of ACC in Y79 and WERI retinoblastoma cells in vitro. (A and B) Y79 and WERI retinoblastoma cells were treated with $2.5,5$ and $10 \mathrm{mM}$ metformin for $48 \mathrm{~h}$. Western blot analysis showed activation of phospho-ACC in a dosedependent manner in treated cells compared to control cells. Data are representative of two independent experiments. Density values of the bands are graphically expressed relative to control. Data are presented as mean \pm SEM $(n=4)$. 
A

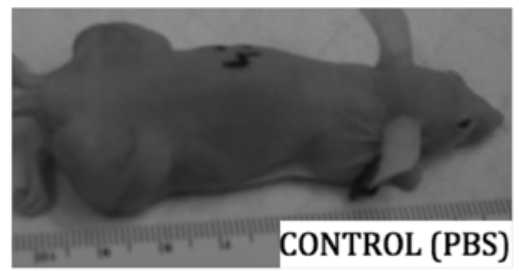

C

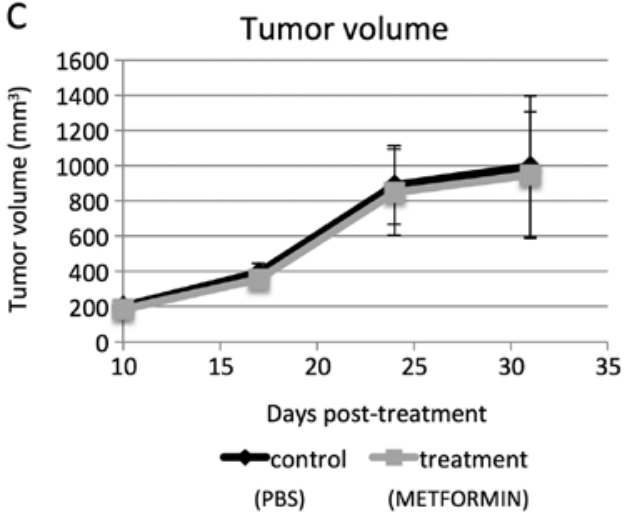

B

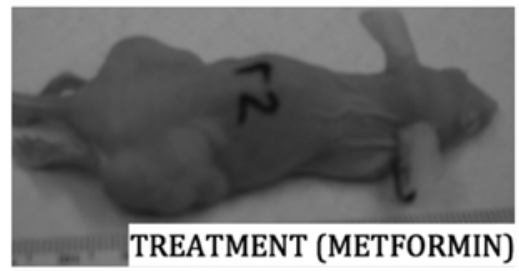

D

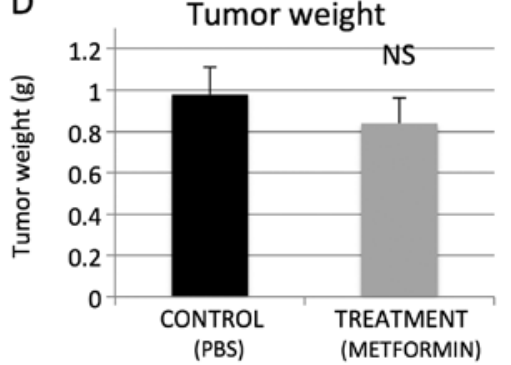

$\mathrm{E}$

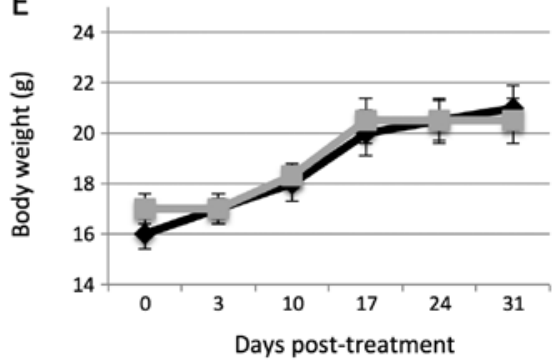

Figure 9. Metformin does not cause statistically significant inhibition of growth of xenografted tumors of Y79 human retinoblastoma cells in nu/nu immune-deficient mice. Human retinoblastoma Y79 cell heterotopic transplanted tumors were developed as described in Materials and methods. Mice were treated with metformin for 31 days. (A) Macroscopic appearance of the mice 31 days after transplantation of Y79 cells, without metformin treatment and (B) with $250 \mathrm{mg} / \mathrm{kg} /$ day treatment of metformin. (C) Tumor growth curves: mean volumes of PBS- vs. metformin-treated group on days indicated did not differ significantly. (D) Mean weights of tumors at autopsy of mice treated with PBS or metformin did not differ significantly. (E) Body weight of mice transplanted with Y79 cells with or without metformin treatment was not different.

directly without involvement of TSC2 after stimulation with pharmacological agent or with nutrient deprivation/stress (64). Indeed, in our study metformin activated the AMPK pathway in retinoblastoma cell lines at $\mathrm{mM}$ levels, as indicated by ACC phosphorylation and decreased phosphorylation of ribosomal protein S6 (a downstream effector of mTOR) and 4E-BP1 (a downstream effector of S6K). However, those effects were not observed in vivo. Energy deprivation and inhibition of the mTOR pathway (65) regulate autophagy (66), a process that maintains cellular homeostasis. Indeed, $\mathrm{mM}$ dose metformin inhibited the mTOR pathway associated with increased LC3-II expression (an autophagic marker). This is in agreement with some studies which showed that high dose metformin induces autophagy in cancer cells (25), however, others have not observed induction of autophagy (27).

Although use of metformin has been extensively used to study the AMPK pathway, like many pharmacological tools, it may have other unknown functions that are independent of its initially characterized action. Indeed, biguanides do not directly activate AMPK in cell free assays (67), and some studies have suggested that metformin mediates its effects completely independently of AMPK $(24,36,68)$. Thus, to determine which proteins mediate the intracellular effect of metformin, further studies are warranted.

When the in vitro effects of metformin on the cell cycle are examined, it has been demonstrated that cells arrest either in the G1 phase $(24,32,69), \mathrm{S}$ phase (69), and/or increase the proportion of cells in the sub-G0/G1 population (69) depending on the cell type. In our study, cell cycle analysis revealed that metformin treatment led to a significant increase of cells in G0/G1 phase and a decrease in S phase in Y79 cells, but the reverse was seen when WERI were treated with metformin (Fig. 3). Similarly to some researchers (24), we observed decrease of cyclin D1 at mM levels in WERI cell line, but in contrast to those reports, not in Y79 cells despite arrest in G0/G1 (Figs. 3A, 4A and 5A). Additionally, the different cell cycle changes observed in these two cell lines were not associated with any specific cyclin and CDK change, but a rather non-specific global reduction in cyclins (E1, E2, D3 and A2), cyclin-dependent kinase (CDK2 and CDK4) as well as the CDK inhibitors p27 and p21 (Figs. 4, 5 and 6). The downregulation of p27 at $\mathrm{mM}$ doses of metformin in our study is in contrast to research that showed upregulation of $\mathrm{p} 27$ in prostate cancer and ovarian caner cells $(24,70)$, or no effect in breast cancer cells (69). Several studies have also indicated metformin may be involved in regulating the positive cell growth regulator phospho-Akt (69,71-73). In our study, the high (mM) dose of metformin in vitro resulted in variable effects on the two retinoblastoma cell lines. No effect was seen in the Y79 cell line, while in the WERI cell line metformin lead to increased phospho-Akt (Fig. 6D and H). The data on cell cycle, cyclins, and Akt taken together suggest that the in vitro high dose 
F

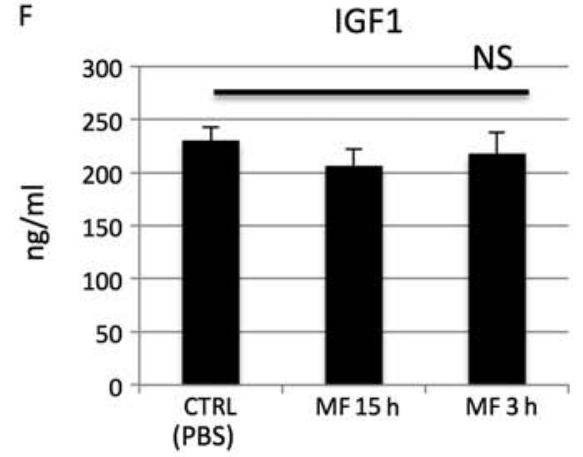

G

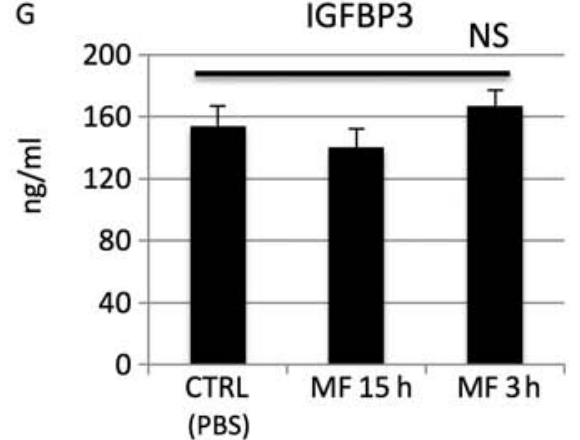

$\mathrm{H}$

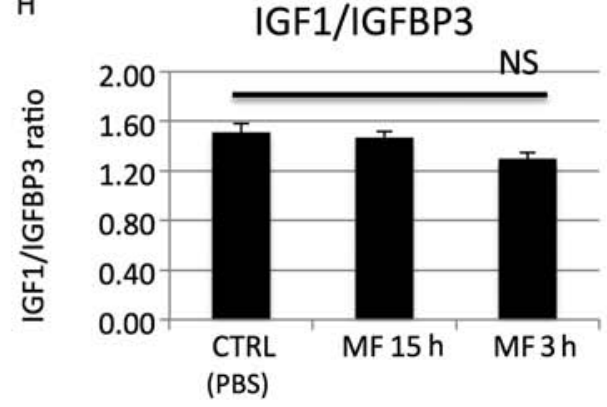

Figure 10. Effect of metformin on AMPK, mTOR and $\mathrm{p} 21$ in vivo. Tumors were collected 3 or $15 \mathrm{~h}$ after the last metformin injection for ELISA testing and proteins were extracted and western blot analysis was performed for indicated proteins. (A) Treatment of metformin did not show activation of AMPK, (B) increased phosphorylation of ACC, $(C$ and $D)$ inhibition of mTOR or (E) downregulation of p21 when compared to PBS treated mice. Data are representative of two independent experiments. Data are presented as mean \pm SEM $(n=4-8)$. (F and G) Serum levels of IGF1 and IGFBP3 of metformin treated mice failed to significantly differ when compared to PBS treated animals. (H) The ratio of IGF1/IGFBP3 did not differ when three groups were compared. Data are the mean \pm SEM ( $\mathrm{n}=5$ ).

metformin effects on cell cycle of retinoblastoma cells may be non-specific.

Most in vitro experiments have shown effects in various cancer cell lines but they typically use concentrations in 2-50 $\mathrm{mM}$, which are much higher than the plasma and tissue concentrations measured in individuals who receive recommended therapeutic doses $(6,11,27,28)$. Studies with $\mu \mathrm{M}$ levels of metformin usually have little effect on cancer cell proliferation, as shown by our study and others $(74,75)$. Yet several epidemiological studies have suggested that patients on metformin may have reduced cancer risk $(76,77)$ and some animal studies have shown effects with $\mu \mathrm{M}$ levels (still almost 10 -fold higher than the levels seen in patients on metformin) (78,79). In these studies $(78,79)$ metformin was used with combination chemotherapy and was shown to have a preferential effect on tumor-forming, self-renewing cancer stem cells, which are resistant to mainstream chemotherapy, yet were found to be sensitive to metformin. Other additional hypothesis claim that metformin exerts its antitumor effects in vivo via its effects on insulin, IGF1 or IGFBP3 (reviewed in ref. 80), however, in our experiments the levels of IGF1, IGFBP3 or IGF1/IGFBP3 ratio remained unchanged (Fig. 10F-H).

Importantly, in our in vivo study, metformin administration lead to levels of the drug equivalent to those seen in patients on metformin, yet we did not detect statistically significant effect on tumor growth, apoptosis, proliferation, vascularity or infiltration by CD11b cells. It is possible that the effects of metformin may be cancer cell specific and/or may involve other pathways in the presence of concurrent chemotherapy. We can not exclude that long-term treatment with metformin may have cancer preventive effects for some cancer types which would be in agreement with some but not all clinical trials $(4,21,23,42,43,58,59)$.

In conclusion, we found that while $\mathrm{mM}$ concentration of metformin inhibit growth of human retinoblastoma cell lines in vitro, $\mu \mathrm{M}$ levels comparable to those achieved in vivo do not. Furthermore, achieving therapeutic levels of metformin in plasma ( $\mu \mathrm{M}$ levels) did not affect tumor growth in xenogratfs in 
A

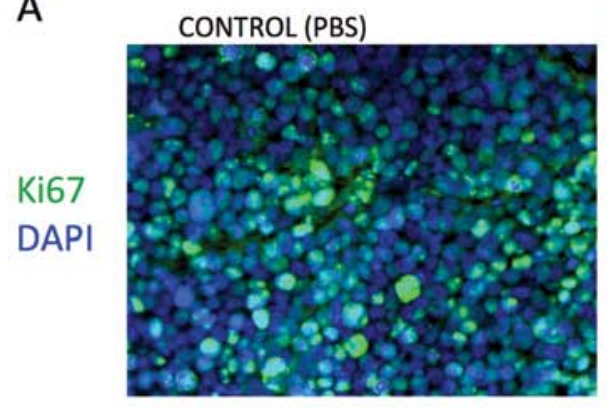

D

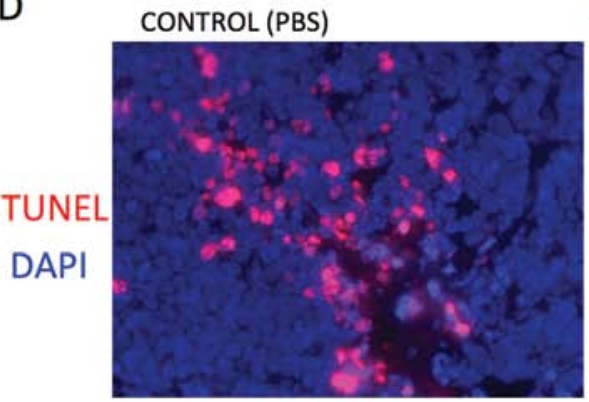

B

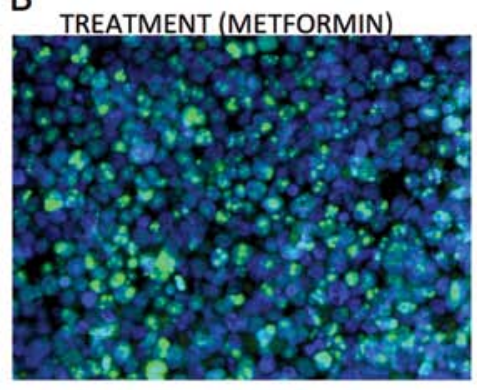

E TREATMENT (METFORMIN)

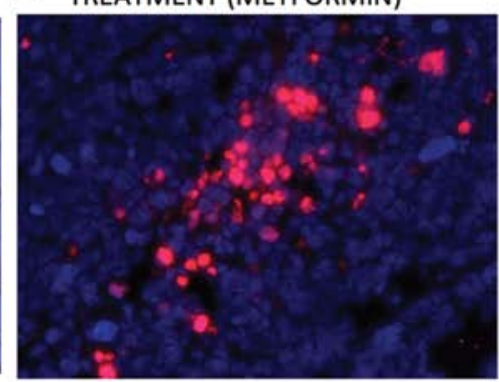

C

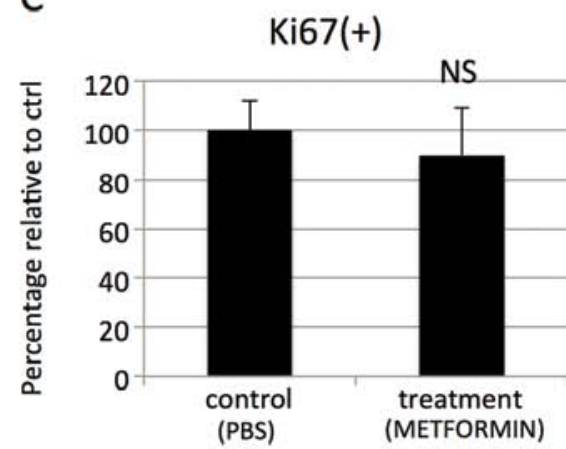

$\mathrm{F}$

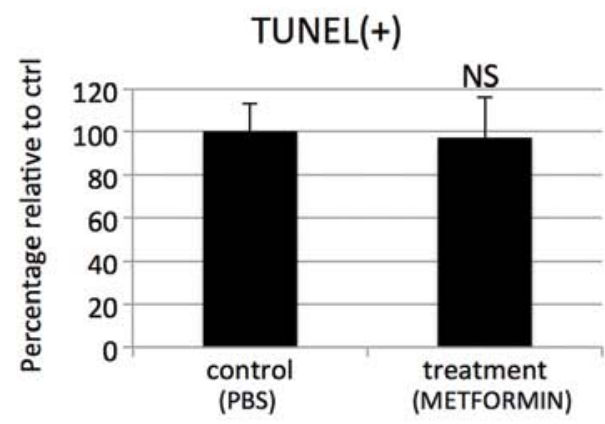

Figure 11. Metformin does not significantly alter proliferation or apoptosis of Y79-derived tumors xenografted into Balb/c nude mice. (A and B) Immunohistochemistry sections of representative tumors with Ki67 and (C and D) TUNEL staining. Nuclei were stained with DAPI (blue). (C-F) Quantitative analysis of Ki67(+)cells/DAPI(+) cells ratio and TUNEL $(+)$ cells/DAPI $(+)$ cells ratio in tumors was performed and results are expressed as a percentage of control. There was no difference between control and treated tumors when quantification was performed for (C) Ki67 and (F) TUNEL. Data are the mean \pm SEM; Ki67 $\mathrm{p}=0.38(\mathrm{n}=5)$; TUNEL $\mathrm{p}=0.46(\mathrm{n}=5)$. Scale bars, $200 \mu \mathrm{m}$.

A

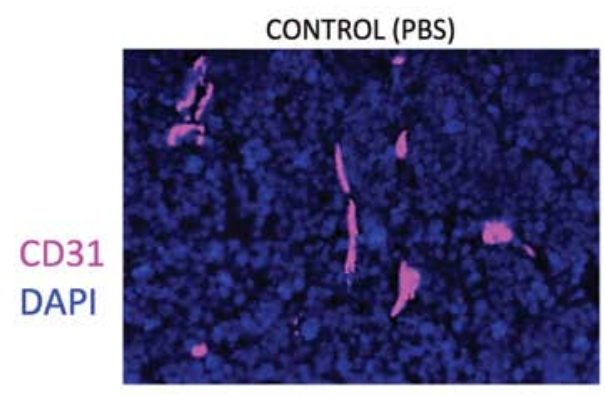

D

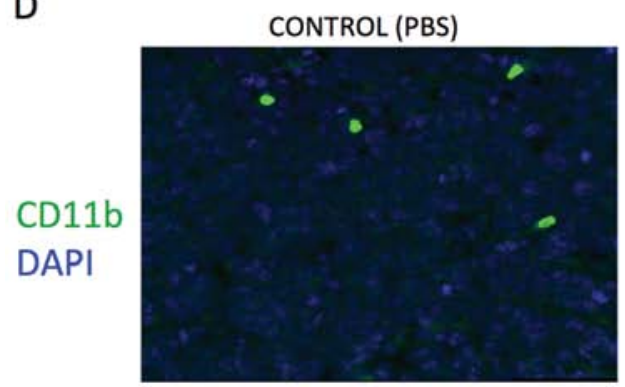

B

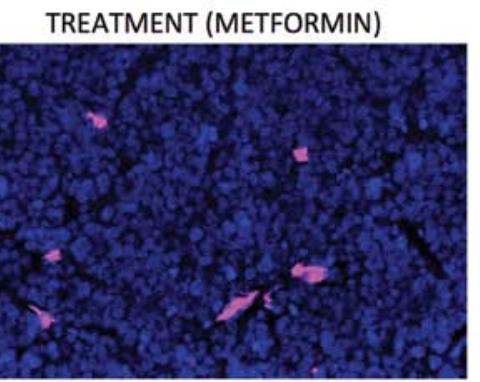

E TREATMENT (METFORMin)

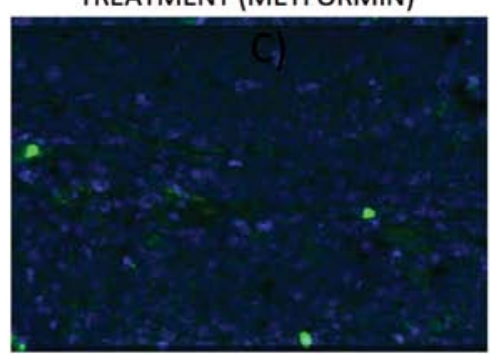

C
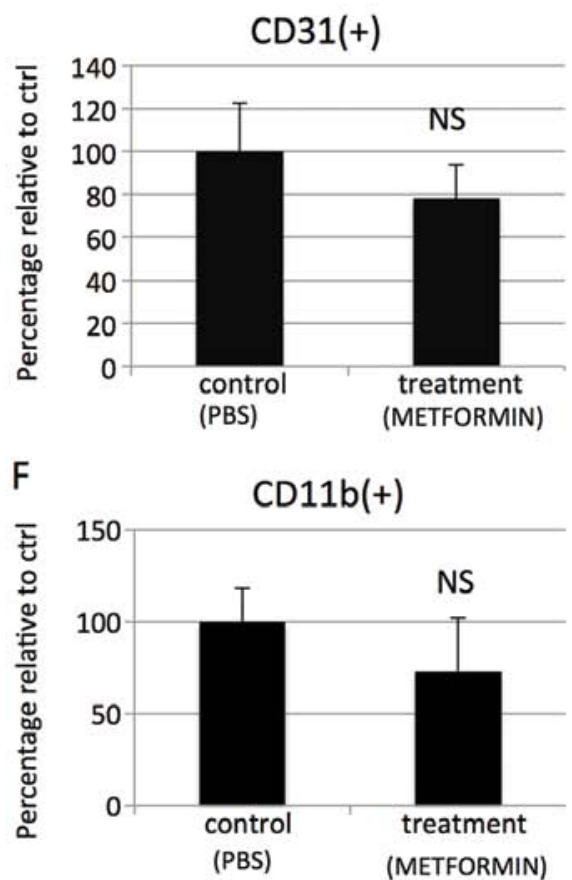

Figure 12. Metformin does not alter vascularity (CD31) or macrophage infiltration of xenografted tumors of Y79 human retinoblastoma in Balb/c nude mice. (A and B) Immunohistochemistry sections of representative tumors with CD31 and (D and E) CD11b nuclei stained with DAPI (blue). (C) Quantitative analysis of CD31(+)cells/DAPI(+) cell ratio and (D) CD11b(+)cells/DAPI(+) cell ratio in tumors was performed and results are expressed as a percentage of control. There was no statistically significant difference between control and treated tumors when quantification was performed for CD31 and CD11b. Data are presented as the mean \pm SEM; CD31 p=0.14 $(\mathrm{n}=5)$ and CD11b p=0.34 $(\mathrm{n}=5)$; Scale bars, $200 \mu \mathrm{m}$. 
$\mathrm{Balb} / \mathrm{c}$ nude mice. Analysis of molecular signal changes suggests that the effects seen in vitro at $\mathrm{mM}$ metformin concentrations are possibly non-specific and due to the very high drug dose causing toxicity. Any potential beneficial effects of metformin seen in some, but not other, epidemiological studies of cancer require extensive further investigation with careful attention to the tumor type, as well as other indirect effects and mechanisms.

\section{Acknowledgements}

This study was supported by National Eye Institute grant EY014104 (MEEI Core Grant), an unrestricted grant to the institution by the Research to Prevent Blindness Foundation (RPB), a Physician Scientist Award by RPB to D.G.V. and by the Massachusetts Lions Eye Research Fund.

\section{References}

1. Broaddus E, Topham A and Singh AD: Incidence of retinoblastoma in the USA: 1975-2004. Br J Ophthalmol 93: 21-23, 2009.

2. Rodriguez-Galindo CC, Wilson MWM,Haik BGB, et al: Treatment of metastatic retinoblastoma. Ophthalmology 110: 1237-1240, 2003.

3. Roarty JD, McLean IW and Zimmerman LE: Incidence of second neoplasms in patients with bilateral retinoblastoma. Ophthalmology 95: 1583-1587, 1988.

4. Shaw RJ, Lamia KA, Vasquez D, et al: The kinase LKB1 mediates glucose homeostasis in liver and therapeutic effects of metformin. Science 310: 1642-1646, 2005.

5. Marr BP, Hung C, Gobin YP, Dunkel IJ, Brodie SE and Abramson DH: Success of intra-arterial chemotherapy (chemosurgery) for retinoblastoma: effect of orbitovascular anatomy. Arch Ophthalmol 130: 180-185, 2012.

6. Liu J, Li M, Song B, et al: Metformin inhibits renal cell carcinoma in vitro and in vivo xenograft. Urol Oncol 31: 264-270, 2013.

7. Bianciotto C, Shields CL, Iturralde JC, Sarici A, Jabbour P and Shields JA: Fluorescein angiographic findings after intra-arterial chemotherapy for retinoblastoma. Ophthalmology 119: 843-849, 2012.

8. Muen WJ, Kingston JE, Robertson F, Brew S, Sagoo MS and Reddy MA: Efficacy and complications of super-selective intra-ophthalmic artery melphalan for the treatment of refractory retinoblastoma. Ophthalmology 119: 611-616, 2012.

9. Miyano-Kurosaki N, Kurosaki K, Hayashi M, et al: 2-aminophenoxazine-3-one suppresses the growth of mouse malignant melanoma B16 cells transplanted into C57BL/6Cr Slc mice. Biol Pharm Bull 29: 2197-2201, 2006.

10. Ghassemi F and Shields CL: Intravitreal melphalan for refractory or recurrent vitreous seeding from retinoblastoma. Arch Ophthalmol 130: 1268-1271, 2012.

11. Qu Z, Zhang Y, Liao M, Chen Y, Zhao J and Pan Y: In vitro and in vivo antitumoral action of metformin on hepatocellular carcinoma. Hepatol Res 42: 922-933, 2012.

12. Munier FL, Gaillard M-C, Balmer A, et al: Intravitreal chemotherapy for vitreous disease in retinoblastoma revisited: from prohibition to conditional indications. Br J Ophthalmol 96: 1078-1083, 2012.

13. Shields CLC, Honavar SGS, Shields JAJ, Demirci HH, Meadows ATA and Naduvilath TJT: Factors predictive of recurrence of retinal tumors, vitreous seeds, and subretinal seeds following chemoreduction for retinoblastoma. Arch Ophthalmol 120: 460-464, 2002.

14. Shields CL, Shelil A, Cater J, Meadows AT and Shields JA: Development of new retinoblastomas after 6 cycles of chemoreduction for retinoblastoma in 162 eyes of 106 consecutive patients. Arch Ophthalmol 121: 1571-1576, 2003.

15. Sussman DA, Escalona-Benz E, Benz MS, et al: Comparison of retinoblastoma reduction for chemotherapy vs external beam radiotherapy. Arch Ophthalmol 121: 979-984, 2003.

16. Schefler AC, Cicciarelli N, Feuer W, Toledano S and Murray TG: Macular retinoblastoma: evaluation of tumor control, local complications, and visual outcomes for eyes treated with chemotherapy and repetitive foveal laser ablation. Opthalmology 114 162-169, 2007
17. Shields CL: Forget-me-nots in the care of children with retinoblastoma. Semin Ophthalmol 23: 324-334, 2009.

18. Shields CL, Palamar M, Sharma P, et al: Retinoblastoma regression patterns following chemoreduction and adjuvant therapy in 557 tumors. Arch Ophthalmol 127: 282-290, 2009.

19. Benz MS, Scott IU, Murray TG, Kramer D and Toledano S: Complications of systemic chemotherapy as treatment of retinoblastoma. Arch Ophthalmol 118: 577-578, 2000.

20. Nishimura S, Sato T, Ueda $H$ and Ueda K: Acute myeloblastic leukemia as a second malignancy in a patient with hereditary retinoblastoma. J Clin Oncol 19: 4182-4183, 2001.

21. Stumvoll M, Nurjhan N, Perriello G, Dailey G and Gerich JE: Metabolic effects of metformin in non-insulin-dependent diabetes mellitus. N Engl J Med 333: 550-554, 1995.

22. Zhou G, Myers R, Li Y, et al: Role of AMP-activated protein kinase in mechanism of metformin action. J Clin Invest 108: 1167-1174, 2001.

23. Hundal HS, Ramlal T, Reyes R, Leiter LA and Klip A: Cellular mechanism of metformin action involves glucose transporter translocation from an intracellular pool to the plasma membrane in L6 muscle cells. Endocrinology 131: 1165-1173, 1992.

24. Sahra IB, Laurent K, Loubat A, et al: The antidiabetic drug metformin exerts an antitumoral effect in vitro and in vivo through a decrease of cyclin D1 level. Oncogene 27: 3576-3586, 2008.

25. Buzzai M, Jones RG, Amaravadi RK, et al: Systemic treatment with the antidiabetic drug metformin selectively impairs p53-deficient tumor cell growth. Cancer Res 67: 6745-6752, 2007.

26. Cufi S, Corominas-Faja B, Vazquez-Martin A, et al: Metformin-induced preferential killing of breast cancer initiating $\mathrm{CD} 44^{+} \mathrm{CD} 24^{-/ \mathrm{low}}$ cells is sufficient to overcome primary resistance to trastuzumab in HER $2^{+}$human breast cancer xenografts. Oncotarget 3: 395-398, 2012.

27. Tomic T, Botton T, Cerezo M, et al: Metformin inhibits melanoma development through autophagy and apoptosis mechanisms. Cell Death Dis 2: e199, 2011.

28. Kato K, Gong J, Iwama H, et al: The antidiabetic drug metformin inhibits gastric cancer cell proliferation in vitro and in vivo. Mol Cancer Ther 11: 549-560, 2012.

29. Martin MJ, Hayward R, Viros A and Marais R: Metformin accelerates the growth of BRAF V600E-driven melanoma by upregulating VEGF-A. Cancer Discov 2: 344-355, 2012.

30. Phoenix KN, Vumbaca F and Claffey KP: Therapeutic metformin/AMPK activation promotes the angiogenic phenotype in the ERalpha negative MDA-MB-435 breast cancer model. Breast Cancer Res Treat 113: 101-111, 2009.

31. Zakikhani M, Dowling R, Fantus IG, Sonenberg N and Pollak M: Metformin is an AMP kinase-dependent growth inhibitor for breast cancer cells. Cancer Res 66: 10269-10273, 2006.

32. Zhuang Y and Miskimins WK: Cell cycle arrest in metformin treated breast cancer cells involves activation of AMPK, downregulation of cyclin D1, and requires p27Kip1 or p21Cip1. J Mol Signal 3: 18, 2008.

33. Towler MC and Hardie DG: AMP-activated protein kinase in metabolic control and insulin signaling. Circ Res 100: 328-341, 2007.

34. Vijg $\mathrm{J}$ and Campisi $\mathrm{J}$ : Puzzles, promises and a cure for ageing. Nature 454: 1065-1071, 2008

35. Moruno-Manchón JF, Pérez-Jiménez E and Knecht E: Glucose induces autophagy under starvation conditions by a p38 MAPK-dependent pathway. Biochem J 449: 497-506, 2013.

36. Hardie DG: The LKB1-AMPK pathway-friend or foe in cancer? Cancer Cell 23: 131-142, 2013.

37. Doyle A, Zhang G, Abdel Fattah EA, Eissa NT and Li YP: Toll-like receptor 4 mediates lipopolysaccharide-induced muscle catabolism via coordinate activation of ubiquitin-proteasome and autophagy-lysosome pathways. FASEB J 25: 99-110, 2011.

38. Matsuzawa T, Kim B-H, Shenoy AR, Kamitani S, Miyake M and Macmicking JD: IFN- $\gamma$ elicits macrophage autophagy via the p38 MAPK signaling pathway. J Immunol 189: 813-818, 2012.

39. Webber JL and Tooze SA: Coordinated regulation of autophagy by p38alpha MAPK through mAtg9 and p38IP. EMBO J 29: 27-40, 2010.

40. Thyagarajan A, Jedinak A, Nguyen H, et al: Triterpenes from Ganoderma Lucidum induce autophagy in colon cancer through the inhibition of p38 mitogen-activated kinase (p38 MAPK). Nutr Cancer 62: 630-640, 2010. 
41. Osborne CK, Bolan G, Monaco ME and Lippman ME: Hormone responsive human breast cancer in long-term tissue culture: effect of insulin. Proc Natl Acad Sci USA 73: 4536-4540, 1976.

42. Metformin insert: 1-6, 2009. Distributed by: Bristol-Myers Squibb Company Princeton, NJ 08543, USA. http://packageinserts.bms. com/pi/pi_glucophage_xr.pdf

43. Quinn BJ, Kitagawa H, Memmott RM, Gills JJ and Dennis PA: Repositioning metformin for cancer prevention and treatment. Trends Endocrinol Metabol 24: 469-480, 2013.

44. Janjetovic K, Harhaji-Trajkovic L, Misirkic-Marjanovic M, et al: In vitro and in vivo anti-melanoma action of metformin. Eur J Pharmacol 668: 373-382, 2011.

45. Hadad SM, Appleyard V and Thompson AM: Therapeutic metformin/AMPK activation promotes the angiogenic phenotype in the ER $\alpha$ negative MDA-MB-435 breast cancer model. Breast Cancer Res Treat 114: 391-399, 2009.

46. Dool CJ, Mashhedi H, Zakikhani M, et al: IGF1/insulin receptor kinase inhibition by BMS-536924 is better tolerated than alloxan-induced hypoinsulinemia and more effective than metformin in the treatment of experimental insulin-responsive breast cancer. Endocr Relat Cancer 18: 699-709, 2011.

47. Wilcock C and Bailey CJ: Accumulation of metformin by tissues of the normal and diabetic mouse. Xenobiotica 24: 49-57, 1994.

48. Evans JM, Donnelly LA, Emslie-Smith AM, Alessi DR and Morris AD: Metformin and reduced risk of cancer in diabetic patients. BMJ 330: 1304-1305, 2005.

49. Cazzaniga M, Bonanni B, Guerrieri-Gonzaga A and Decensi A: Is it time to test metformin in breast cancer clinical trials? Cancer Epidemiol Biomarkers Prev 18: 701-705, 2009.

50. Noto H, Goto A, Tsujimoto T and Noda M: Cancer risk in diabetic patients treated with metformin: a systematic review and meta-analysis. PLoS One 7: e33411, 2012.

51. Becker C, Meier CR, Jick SS and Bodmer M: Case-control analysis on metformin and cancer of the esophagus. Cancer Causes Control 24: 1763-1770, 2013.

52. Becker C, Jick SS, Meier CR and Bodmer M: Metformin and the risk of endometrial cancer: a case-control analysis. Gynecol Oncol 129: 565-569, 2013.

53. Bodmer M, Becker C, Jick SS and Meier CR: Metformin does not alter the risk of lung cancer: a case-control analysis. Lung Cancer 78: 133-137, 2012

54. Bodmer M, Becker C, Meier C, Jick SS and Meier CR: Use of metformin is not associated with a decreased risk of colorectal cancer: a case-control analysis. Cancer Epidemiol Biomarkers Prev 21: 280-286, 2012.

55. Kaushik D, Karnes RJ, Eisenberg MS, Rangel LJ, Carlson RE and Bergstralh EJ: Effect of metformin on prostate cancer outcomes after radical prostatectomy. Urol Oncol 32: 43.e1-7, 2013.

56. Bodmer M, Becker C, Meier C, Jick SS and Meier CR: Use of antidiabetic agents and the risk of pancreatic cancer: a case-control analysis. Am J Gastroenterol 107: 620-626, 2012.

57. Mazzone PJ, Rai H, Beukemann M, Xu M, Jain A and Sasidhar M: The effect of metformin and thiazolidinedione use on lung cancer in diabetics. BMC Cancer 12: 410, 2012

58. Bodmer M, Becker C, Meier C, Jick SS and Meier CR: Use of metformin and the risk of ovarian cancer: a case-control analysis. Gynecol Oncol 123: 200-204, 2011.

59. Bodmer M, Meier C, Krähenbühl S, Jick SS and Meier CR: Long-term metformin use is associated with decreased risk of breast cancer. Diabetes Care 33: 1304-1308, 2010.

60. Tomimoto A, Endo H, Sugiyama M, et al: Metformin suppresses intestinal polyp growth in $\mathrm{Apc}^{\mathrm{Min} /+}$ mice. Cancer Science 99: 2136-2141,2008.

61. Theodoropoulou S, Kolovou PE, Morizane Y, et al: Retinoblastoma cells are inhibited by aminoimidazole carboxamide ribonucleotide (AICAR) partially through activation of AMP-dependent kinase. FASEB J 24: 2620-2630, 2010.
62. Rattan R, Giri S, Singh AK and Singh I: 5-Aminoimidazole4-carboxamide-1-beta-D-ribofuranoside inhibits cancer cell proliferation in vitro and in vivo via AMP-activated protein kinase. J Biol Chem 280: 39582-39593, 2005.

63. Inoki KK, Zhu TT and Guan K-LK: TSC2 mediates cellular energy response to control cell growth and survival. Cell 115: 577-590, 2003 .

64. Cheng SWY, Fryer LGD, Carling D and Shepherd PR: Thr2446 is a novel mammalian target of rapamycin (mTOR) phosphorylation site regulated by nutrient status. J Biol Chem 279: 15719-15722, 2004.

65. Sarbassov DD, Ali SM and Sabatini DM: Growing roles for the mTOR pathway. Curr Opin Cell Biol 17: 596-603, 2005.

66. Kondo Y, Kanzawa T, Sawaya R and Kondo S: The role of autophagy in cancer development and response to therapy. Nat Rev Cancer 5: 726-734, 2005.

67. Hawley SA, Gadalla AE, Olsen GS and Hardie DG: The antidiabetic drug metformin activates the AMP-activated protein kinase cascade via an adenine nucleotide-independent mechanism. Diabetes 51: 2420-2425, 2002.

68. Kalender A, Selvaraj A, Kim SY, et al: Metformin, independent of AMPK, inhibits mTORC1 in a rag GTPase-dependent manner. Cell Metab 11: 390-401, 2010.

69. Liu B, Fan Z, Edgerton SM, et al: Metformin induces unique biological and molecular responses in triple negative breast cancer cells. Cell Cycle 8: 2031-2040, 2009.

70. Li C, Liu VWS, Chan DW, Yao KM and Ngan HYS: LY294002 and metformin cooperatively enhance the inhibition of growth and the induction of apoptosis of ovarian cancer cells. Int $\mathrm{J}$ Gynecol Cancer 22: 15-22, 2012.

71. Capano $\mathrm{M}$ and Crompton M: Bax translocates to mitochondria of heart cells during simulated ischaemia: involvement of AMP-activated and p38 mitogen-activated protein kinases. Biochem J 395: 57-64, 2006.

72. Xi X, Han J and Zhang JZ: Stimulation of glucose transport by AMP-activated protein kinase via activation of p38 mitogen-activated protein kinase. J Biol Chem 276: 41029-41034, 2001.

73. Würth R, Pattarozzi A, Gatti M, et al: Metformin selectively affects human glioblastoma tumor-initiating cell viability: A role for metformin-induced inhibition of Akt. Cell Cycle 12: 145-156, 2013

74. Bao B, Wang Z, Ali S, et al: Metformin inhibits cell proliferation, migration and invasion by attenuating CSC function mediated by deregulating miRNAs in pancreatic cancer cells. Cancer Prevent Res 5: 355-364, 2012.

75. Ben Sahra I, Regazzetti C, Robert G, et al: Metformin, independent of AMPK, induces mTOR inhibition and cell-cycle arrest through REDD1. Cancer Res 71: 4366-4372, 2011.

76. Soranna D, Scotti L, Zambon A, et al: Cancer risk associated with use of metformin and sulfonylurea in type 2 diabetes: a meta-analysis. Oncologist 17: 813-822, 2012.

77. Bost F, Sahra IB, Le Marchand-Brustel Y and Tanti JF: Metformin and cancer therapy. Curr Opin Oncol 24: 103-108, 2012.

78. Iliopoulos D, Hirsch HA and Struhl K: Metformin decreases the dose of chemotherapy for prolonging tumor remission in mouse xenografts involving multiple cancer cell types. Cancer Res 71: 3196-3201, 2011.

79. Hirsch HA, Iliopoulos D, Tsichlis PN and Struhl K: Metformin selectively targets cancer stem cells, and acts together with chemotherapy to block tumor growth and prolong remission. Cancer Res 69: 7507-7511, 2009.

80. Martin-Castillo B, Vazquez-Martin A, Oliveras-Ferraros C and Menendez JA: Metformin and cancer: doses, mechanisms and the dandelion and hormetic phenomena. Cell Cycle 9: 1057-1064, 2010 